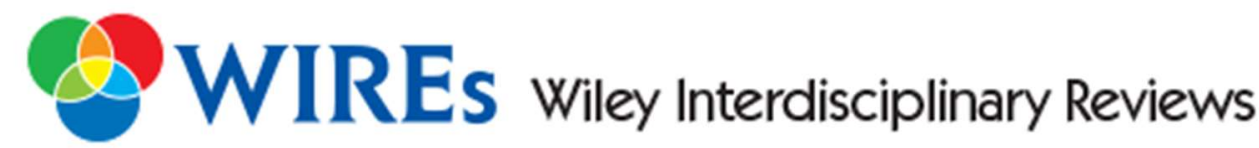

This is the peer reviewed version of the following article:

Bleay, S. M., Bailey, M. J., Croxton, R. S., \& Francese, S. (in press). The forensic exploitation of fingermark chemistry: A review. WIREs Forensic Science,

which has been published in final form at https://doi.org/10.1002/wfs2.1403. This article may be used for non-commercial purposes in accordance with Wiley Terms and Conditions for Use of Self-Archived Versions.

\section{Article Title: The forensic exploitation of fingermark chemistry: a review}

\section{Authors:}

\author{
First author* \\ Stephen M. Bleay, https://orcid.org/0000-0002-9176-5337, London South Bank \\ University, bleays@lsbu.ac.uk \\ Second author \\ Melanie J. Bailey, https://orcid.org/0000-0001-9050-7910, University of Surrey, \\ m.bailey@surrey.ac.uk \\ Third author \\ Ruth S. Croxton, https://orcid.org/0000-0002-4027-7077, University of Hull, \\ R.Croxton@hull.ac.uk \\ Fourth author \\ Simona Francese, http://orcid.org/0000-0002-1381-1262, Sheffield Hallam University, \\ S.Francese@shu.ac.uk
}

\section{Abstract}

The substances deposited from the fingertip onto a surface during contact between them represent a highly complex range of chemicals that can be exploited in a variety of ways in a forensic investigation. An overview is given of the multitude of chemicals that have been detected in fingermarks, including those occurring in endogenous sweat, metabolites of ingested substances, and exogenous substances picked up on the fingertip. Changes in chemistry that may occur between deposition of the fingermark and its subsequent forensic analysis are discussed, with particular reference to the ways in which these changes have been considered as a means of dating fingermarks. The ways in which fingermark enhancement reagents utilise the different chemicals present to reveal ridge is reviewed, together with how different classes of chemical can be sequentially targeted to optimise the number of fingermarks recovered. A field of increasing interest is the use of advanced analytical techniques incorporating mass spectrometry and imaging capability to simultaneously obtain additional contextual information about the donor of the mark whilst visualising the fingermark ridge pattern. Examples are given of how such information can be applied in forensic investigations. It is concluded that an extensive 'tool kit' of fingermark enhancement 
processes is already available to utilise the different chemicals present, and the advances that can be made in this field using conventional approaches are limited. There is, instead, significant potential to utilise analytical techniques to forensically exploit the chemical information within fingermarks but there are also significant barriers to their implementation in this way.

Keywords: Fingermark chemistry, fingermark enhancement, forensic exploitation, mass spectrometry, chemical imaging, lifestyle

\section{Graphical/Visual Abstract and Caption}

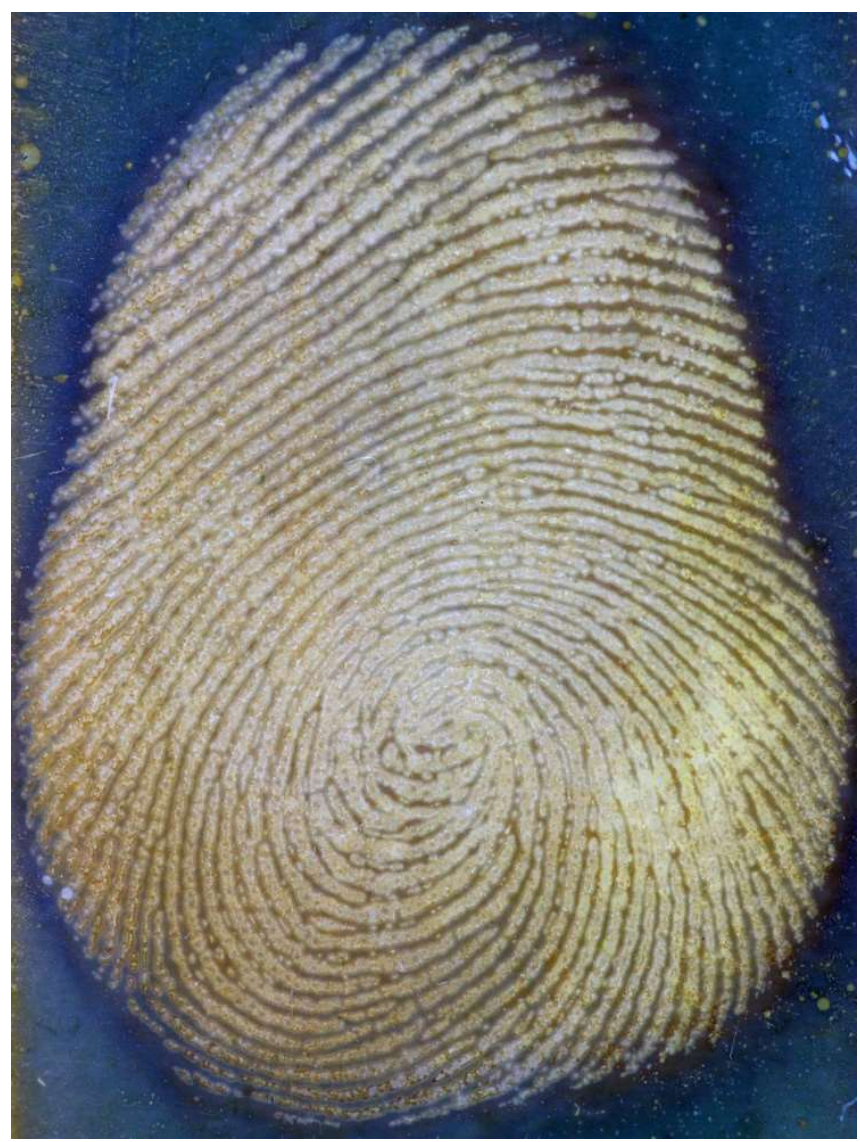

A sebum-rich thumb mark deposited on a glass slide and developed using silver vacuum metal deposition. The mark shows the Level 1, Level 2 and Level 3 detail used for fingerprint comparison and identification. The differences in colour in the ridges indicate variations in thickness and composition of the substances deposited.

\section{INTRODUCTION}

There is evidence that the use of fingerprints for the identification of an individual, either for civil or criminal purposes, has been considered in some form for over 2000 years (Barnes, 2011). The comparison of a mark left by an individual at a crime scene with sets of reference prints taken under controlled conditions is a cornerstone of forensic investigation, first being proposed in 1880 (Faulds, 1880). Following the generation of classification systems for fingerprint patterns (Galton, 1892) and filing systems enabling databases to be searched (Henry, 1901), fingerprint comparison and 
identification has been successfully employed for over 120 years. The fact that fingerprint patterns are 'unique' (to the best of scientific knowledge) and persistent throughout life makes them a powerful identification tool. Indeed, the term 'fingerprint' is widely used across many other branches of science, for example, the mid-infrared spectrum of organic substances is often referred to as a form of chemical "fingerprint" because it is sufficiently characteristic to a particular substance to enable it to be identified.

In criminal investigations the focus is on locating marks that may have been left by the suspect at the crime scene. These can be of three principal types; a positive mark where material is transferred from the fingertip to the surface, a negative mark where the fingertip removes material (e.g. dust) from the surface, or a 'plastic' mark where the fingertip leaves a permanent impression in a soft substance such as putty. The classification of a positive mark can be further divided into a 'patent' mark where the material transferred is readily visible to the eye (e.g. mud, ink), or a 'latent' mark where the material transferred cannot typically be readily seen by eye and needs further enhancement to be seen.

The chemistry of the material transferred from the finger to the surface is important to the visualisation of the contact trace. This is because chemical substances present can be utilised by a range of processes that either convert a latent mark into one that is visible or assist in further enhancing the pre-existing detail in a patent mark. The chemical development of fingermarks was observed as early as the 1860 s (Quinche \& Margot, 2010) and was already being explored in a more focused way in the 1920s (Mitchell, 1920), with a range of chemical processes targeting different constituents being proposed for use.

In the forensic community, there is some debate over the exact definition of the terms fingerprint and fingermark. Here, we define a fingermark to be a trace that is on a surface at a crime scene. For a fingermark, the circumstances of deposition are unknown. Once the fingermark has been developed and photographed, the ridge patterns are normally compared to an inked fingerprint, given by a known donor. In contrast to a fingermark, a fingerprint can deposited under controlled conditions - for example by controlling the contact time, pressure and cleanliness of both the finger and the surface. In this review, a fingermark refers to a mark deposited in an uncontrolled manner by an unknown donor, whereas a fingerprint is deposited in a controlled manner by a known donor.

This review will focus on the material that is ultimately transferred from the fingertip to the surface to form a fingermark. It will consider how this highly complex chemistry can be utilised by a wide range of chemical reagents, and by advanced analytical techniques in combination with imaging capabilities, to reveal the fingermark ridge detail and additional information contained within it.

\section{FINGERMARK CHEMISTRY}

Before progressing to a discussion of the composition of the material that may be transferred during contact, it is necessary to consider the quantity of material that is actually transferred. There have been few studies that address this important aspect.

Early work focused on estimations of the mass of a single fingermark or examining the loss of mass over time due to drying of the sample and evaporation of water (Cuthbertson and Morris, 1972; 
Scruton et al., 1975; Darke and Wilson, 1977). However, it was not possible to extrapolate the mass of a single latent fingermark using the approaches proposed at that time. In 2008 a study determined the mass of a single natural latent fingermark collected on a non-porous substrate using a microbalance with a readability of $0.1 \mu \mathrm{g}$ (Croxton, 2008). Fingermark mass was found to range between 0.33 and $29.00 \mu \mathrm{g}$ (mean $7.40 \mu \mathrm{g}$, s.d. $7.46 \mu \mathrm{g}, \mathrm{n}=55$ fingermarks from seven donors). Over a 24 hour period a loss in mass was observed for some fingermarks, as well as an increase in mass in others. The latter was thought to be due to hydration of the fingermark due to the presence of hygroscopic constituents. Additionally, Bright et al. (2013) observed that fingermarks that were placed into a vacuum system lost around $26 \%$ of their mass - equivalent to 5 weeks ageing under ambient conditions.

Watkinson (2018) found that the chemical composition of sequential fingermarks from the same individual, donated under controlled conditions can be reproducible. The variability in the mass of fingermark depositions was found to vary by up to $100 \%$ within donors. However, if a donor washed their hands prior to depositing a fingermark, the variability in deposited mass reduced to $21 \%$.

Additionally, it was found that the chemical composition of sequential depositions was also relatively reproducible, provided hands were washed prior to providing a fingermark.

It is now well known that the composition of latent fingermarks is complex. Latent fingermarks consist of chemical contributions from a number of natural sources, predominantly the eccrine and sebaceous glands, in varying relative amounts with minor contributions at times from the apocrine sweat glands and the epidermis (Table 1). Contributions from external sources such as cosmetics, hair and tobacco products and any other contaminant the fingertips may come into contact with, further increase the complexity. This complexity, however, provides the opportunity for latent fingermarks to be exploited for information about the donor and/or their habits.

Table 1: Summary of endogenous latent fingermark residue constituents and their sources

\begin{tabular}{|c|c|c|}
\hline Source & Organic constituents & Inorganic constituents \\
\hline Eccrine sweat & $\begin{array}{l}\text { Amino acids (e.g. serine, glycine, } \\
\text { ornithine, alanine, aspartic acid); Creatine; } \\
\text { Creatinine; Enzymes (e.g. esterases, } \\
\text { proteolytic enzymes); Glucose and other } \\
\text { reducing sugars; Glycogen; Lactic acid and } \\
\text { lactate; Peptides (e.g. dermicidin, } \\
\text { cathelicidin LL-37); Phenol; Proteins (e.g. } \\
\text { albumin, cathepsin D, immunoglobulins } \\
\text { (IgG, IgA, IgD, IgE), keratins } 1 \text { and 10); } \\
\text { Pyruvic acid and pyruvate; Urea; Uric acid; } \\
\text { Vitamins (e.g. ascorbic acid, choline, folic } \\
\text { acid, niacin, riboflavin) }\end{array}$ & $\begin{array}{l}\text { Ammonia; Bicarbonate; Bromide; } \\
\text { Chloride; Fluoride; lodide; Metal ions - } \\
\text { major (e.g. calcium, iron, potassium, } \\
\text { sodium) and trace (e.g. cobalt, copper, } \\
\text { lead, magnesium, zinc); Phosphate; } \\
\text { Sulphate; Sulphide; Water }\end{array}$ \\
\hline Sebum & & $\begin{array}{l}\text { Alcohols; Fatty acids (e.g. palmitic, } \\
\text { palmitoleic, oleic, stearic, myristic acids); } \\
\text { Fatty acid alkyl esters (e.g. palmitic acid } \\
\text { methyl ester, stearic acid methyl ester); }\end{array}$ \\
\hline
\end{tabular}




\begin{tabular}{|c|c|c|}
\hline & & $\begin{array}{l}\text { Glycerides (e.g. mono-, di- and } \\
\text { triglycerides); Hydrocarbons (saturated } \\
\text { and unsaturated); Squalene; Squalene } \\
\text { degradation products (e.g. squalene } \\
\text { epoxides, squalene hydroperoxides); } \\
\text { Sterols (e.g. cholesterol); Sterol esters } \\
\text { (e.g. cholesterol esters); Wax esters (e.g. } \\
\text { myristyl myristate, palmityl palmitoleate, } \\
\text { stearyl palmitate) }\end{array}$ \\
\hline Epidermal lipids & & $\begin{array}{l}\text { Fatty acids; Glycerides; Proteins (e.g. } \\
\text { cathepsin D, keratins } 1 \text { and 10); Sterols } \\
\text { (e.g. cholesterol); Sterol esters (e.g. } \\
\text { cholesterol ester) }\end{array}$ \\
\hline Apocrine sweat & $\begin{array}{l}\text { Androgenic steroids; Carbohydrates e.g. } \\
\text { glycogen; Carboxylic acids; Proteins; } \\
\text { Sterols e.g. cholesterol }\end{array}$ & Ammonia; Iron; Water \\
\hline
\end{tabular}

\subsection{Eccrine sweat}

Since eccrine sweat glands are the only glands found on the palmar region of the hand and fingers, eccrine sweat is often the predominant endogenous component of latent fingermark residue. Water is typically a very high proportion of eccrine sweat with the remainder consisting of a mixture of water-soluble organic compounds and inorganic salts (Table 1). There can be great variation in eccrine sweat composition between donors and within a donor over time, although there are common constituents.

The predominant organic components of eccrine sweat are amino acids and proteins. Amino acid concentration has been reported to be between 0.30 and $2.59 \mathrm{mg} \mathrm{L}^{-1}$ with individual amino acids present in different relative abundances (Hansen and Joullié, 2005). Serine, glycine and alanine are the most abundant. Threonine, leucine, tyrosine, isoleucine, lysine, phenyalanine, methionine and cystine are also present but in decreasingly lower amounts. Quantitative studies of deposited latent fingermarks using a variety of analytical techniques have found comparable amino acid profiles to eccrine sweat (Croxton et al., 2010; Atherton et al., 2012; De Puit et al., 2014; van Helmond et al. 2017).

A variety of other ninhydrin-positive substances have been identified in eccrine sweat (such as cysteic acid, methionine sulphoxide and glucosamine (Liappis and Hungerland, 1973), as well as proteins including albumin, cathepsin D, dermicidin, immunoglobulins (IgG, IgA, IgD and IgE), keratins 1 and 10, and antimicrobial proteins and peptides (O'Neal, Page and Remington, 1967; Nakayashiki, 1990; Flad et al., 2002; Murakami et al., 2002; Drapel et al., 2009). Other organic compounds reported in eccrine sweat include glucose, pyruvic and lactic acid, urea, uric acid, creatinine, creatine and ammonia (Bleay, Croxton \& de Puit, 2018).

The protein component of latent fingermarks has also been studied (Ferguson et al., 2012; Song et al., 2012; Oonk et al., 2018). Dermicidin, the most abundant protein in eccrine sweat, was targeted 
by immunolabelling and revealed a "dotted" fingermark ridge pattern (van Dam et al., 2013).

Ferguson et al. (2012) demonstrated that the use of matrix assisted laser desorption/ionisation mass spectrometry (MALDI MS) could detect many other peptides and protein species, including dermicidin, and psoriasin. By using MALDI MS imaging (MSI), a similar dotted dermicidin molecular image could be provided albeit at lower resolution $(200 \mu \mathrm{m} \times 200 \mu \mathrm{m})$ (Francese, 2015) (Figure 1)
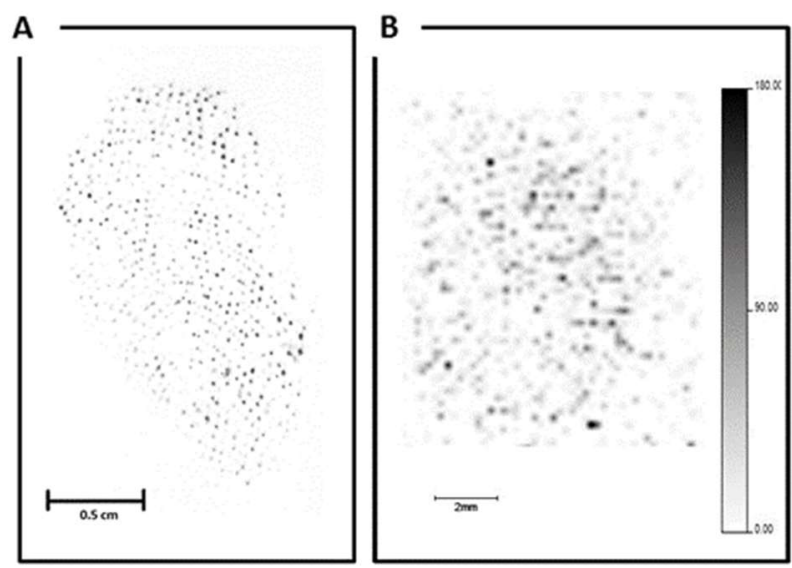

Figure 1. Fingermark images generated by dermicidin peptide. A: immunolabelled dermicidingenerated image of an eccrine mark; B: MALDI MSI image of dermicidin at $m / z$ 4918. (A) was Reprinted/adapted from Forensic Science International, 232/1-3, van Dam A, Aalders MC, van de Braak K, Hardy HJ, van Leeuwen TG, Lambrechts SA, Simultaneous labelling of multiple components in a single fingermark, 173-9., Copyright (2013), with permission from Elsevier; (B) Adapted and reprinted from Francese, S. (2015). Techniques for fingermark analysis using MALDI MS - a practical overview. In R. Kramer (Ed), Advances in MALDI and laser induced soft ionisation mass spectrometry. Springer. Copyright 2016

The most abundant inorganic salt is chloride (predominantly as sodium chloride) with bromide, iodide and fluoride also found. Chloride concentration, in particular, varies greatly with a number physiological factors including anatomical site, sweat rate and dietary and water intake (Rothman, 1954; Olsen, 1972) and has also been shown to vary in latent fingermarks between donors (Cuthbertson, 1969). Other inorganic components found in eccrine sweat include copper, manganese, magnesium, phosphorous, iron and calcium. The spatial distribution of elemental constituents from both endogenous and exogenous sources has been studied in latent fingermarks (Worley et al., 2006; Bailey et al., 2013; Thandauthapani et al., 2018; Boseley et al., 2019).

\subsection{Sebaceous sweat}

Sebum is the secretory product of the sebaceous gland which is found in varying abundance in different anatomical sites. They are most abundant on the scalp and face but absent from the palms of the hands and fingers. Sebum does, however, contribute to latent fingermark residue to varying degrees as a result of the fingertips coming into contact with other parts of the body. The composition of sebum is highly complex and highly variable between individuals. Sebum, together with epidermal lipids, contribute to skin surface lipids which have been extensively studied due to the ease with which samples can be collected. Fatty acids, squalene, wax esters and triglycerides are the major components of sebum (Downing and Strauss, 1974; Downing et al., 1977). Sebaceous 
glands are stimulated by androgens and as such their activity varies with age, affecting the skin surface lipid composition as a consequence. Sebum composition is also affected by pathological conditions (e.g. acne), environmental conditions (e.g. temperature and ultraviolet (UV) irradiation) and microbial colonisation.

Free fatty acids can make up between $16-33 \%$ of skin surface lipids and arise from both sebum and epidermal lipids. Palmitic acid (hexadecanoic, $\mathrm{C} 16: 0$ ) is the most abundant, followed by palmitoleic acid (cis-9-hexadecenoic, C16:1) and oleic acid (cis-9-octadecenoic, C18:1). Myristic (tetradecanoic, C14:0), stearic (octadecanoic, C18:0) and linoleic (cis-9,12-octadecadienoic, C18:2) acids are also abundant (Nicolaides, 1974; Boniforti et al., 1973; Nazzaro-Porro et al., 1979). Wax esters make up $20-27 \%$ of skin surface lipids and are produced exclusively by the sebaceous glands, as well as squalene $(2,6,10,15,19,23$-hexamethyl-2,6,10,14,18,22-tetracosahexaene), a cholesterol intermediate forming $10-15 \%$ of skin surface lipids. Sterols and sterol esters are also found in skin surface lipids, predominantly arising from the epidermal lipids, with cholesterol (cholest-5-en-3 $\beta$-ol, 0.7-2.4\%) and cholesterol ester (2-3.3\%) being the most abundant. Other organic components of skin surface residue include carboxylic acids, short-chain alcohols, aldehydes, alkane, alkenes ketones, aromatic amides, amines and heterocyclics.

The lipid composition of latent fingermarks has been well studied largely due to the ease of analysis of most components. Good correlation has been found between the lipid composition of deposited latent fingermarks and skin surface lipids. The relative composition can vary depending on variables such as amount of contact between fingertips and other parts of the body and thus the level of sebum-contamination picked up. As such inter- and intra-donor variation has been demonstrated in many studies (Archer et al., 2005; Croxton et al., 2010; Weyermann et al., 2011; Bailey et al., 2012; Emmerson et al., 2011; Ferguson et al., 2013; Dorakumbura et al. 2019; Frick \& Weyermann, 2019; O'Neill et al., 2020). The substrate has been shown to affect the amount of material deposited (Weyermann et al., 2011). The method of fingermark extraction and sample preparation can also affect the quantitative data collected for different constituents (Kim et al., 2019).

\subsection{Apocrine sweat}

Apocrine sweat can be found in latent fingermarks as a result of contamination of the fingertips from touching axillary regions of the body (namely the armpit and genital areas) but is not usually a major constituent. Proteins, ammonia, carbohydrates, ferric ions, cholesterol and androgen steroids are the main constituents (Saga, 2002). Since the apocrine sweat glands are not active until puberty, contribution to latent fingermarks will vary with age (Robertshaw, 1991; Saga, 2002).

\subsection{Skin cells and epidermal lipids}

Epidermal lipids arise predominantly from stratum corneum cells and together with sebum, form the skin surface lipids as outlined above. The epidermal contribution is relatively constant for different anatomical sites, whilst that of the sebaceous glands varies due to gland density variation (Rothmann, 1954; Downing and Strauss, 1974). Epidermal lipids consist of large amounts of sterols, sterol esters, glycerides and phospholipids (Downing and Strauss, 1974; Downing et al., 1977). Epidermal lipids contribute to latent fingermarks as a consequence of the fingertips touching other parts of the body and/or migration of material from the back of the hand. 
In addition to epidermal lipids, it is expected that skin cells will also be shed from the fingers and palms in addition to being picked up on the fingers during contact with other parts of the body. Skin cells are more likely to be sloughed from the fingers during contact with rough surfaces and may be more forcefully pulled from the fingertip on contact with adhesive surfaces (Jones et al., 2010). It has also been shown that the quantity of skin cells shed from the palmar region varies, with higher densities of skin cells shed from the fingertips than from the palm (Oleiwi et al., 2015).

\subsection{DNA}

There are multiple sources of DNA in fingermarks, the principal one being skin cells as discussed above. However it has also been shown that there also are significant quantities of cell-free nucleic acids in sweat (on average $11.5 \mathrm{ng}$ of DNA in $1 \mathrm{~mL}$ of cell-free sweat) and these are of a suitable length for standard DNA profiling (Quinones \& Daniel, 2012).

\subsection{Contaminants (exogenous substances) and metabolites}

In addition to the wide range of substances that occur naturally within a fingermark, there are also a countless number of substances that can be picked up on the hand through daily tasks, and also others that will be excreted as metabolites following the ingestion of other substances. Although the balance of natural substances present in a fingermark will vary according to factors such as diet, physical exertion, time of day etc., exogenous substances and metabolites have greater potential to provide additional contextual information about the donor.

Figure 2 shows a series of images of fingertips with different types of contaminant present.
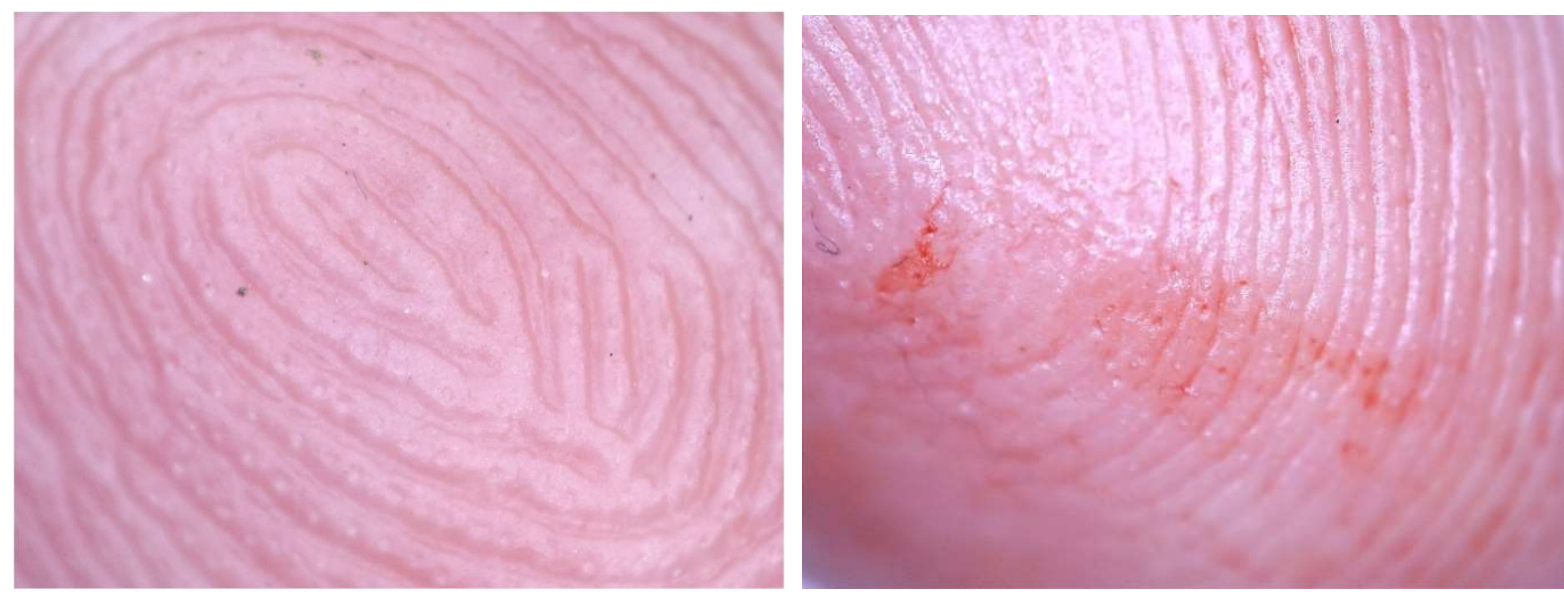

a)

b) 


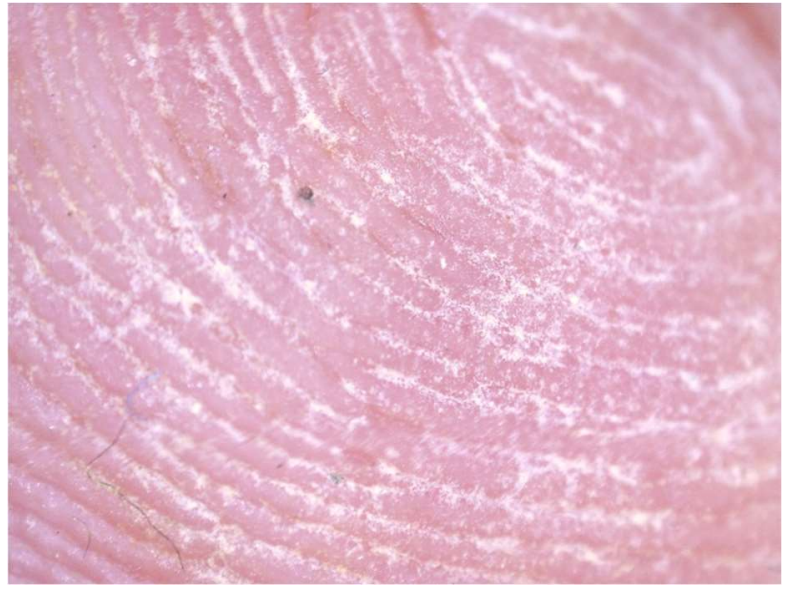

c)

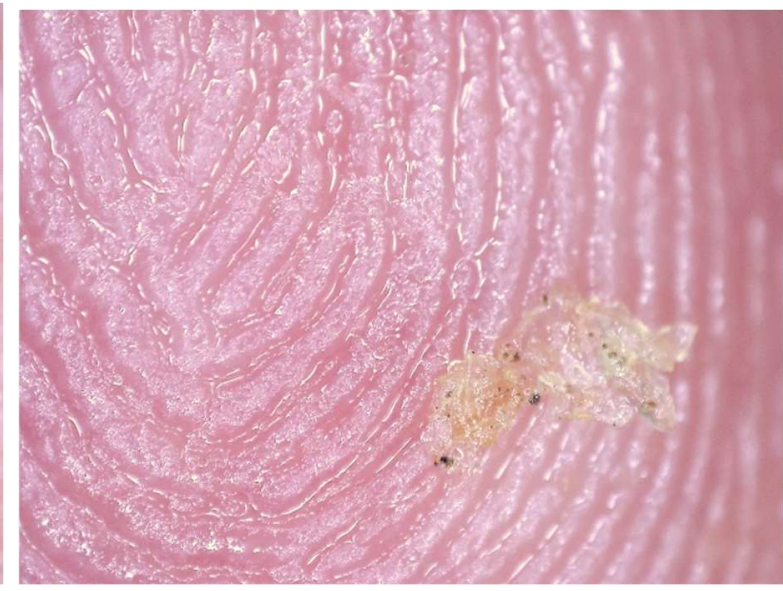

d)

Figure 2. Micrographs (x10) of a fingertip, a) clean fingertip, $b$ ) contaminated with traces of blood, $c$ ) residues from peeling an orange, and d) residues from eating corn chips

The examples given above are only some of the materials that may be found and providing an exhaustive list is not possible here. Blood is probably the most significant contaminant that may be encountered in a fingermark at a crime scene. Some of the other significant contaminants and metabolites that have been detected within fingermarks by different research groups, using a wide range of analytical techniques, are summarised in Tables 2-4 below.

Table 2: Summary of drugs, pharmaceutical and illicit, and their metabolites that have been detected within fingermarks

\begin{tabular}{|c|c|}
\hline Drugs [metabolites] & Reference \\
\hline $\begin{array}{l}\text { Amphetamines: } \\
\text { Amphetamine, methamphetamine, 3,4- } \\
\text { methylenedioxyamphetamine, 3,4-methyl } \\
\text { enedioxymethamphetamine(Ecstasy); }\end{array}$ & $\begin{array}{l}\text { Day et al. (2004a); Day et al. (2004b); Szynkowska et al. } \\
\text { (2009); West \& Went (2009); Szynkowska et al. (2010); } \\
\text { Clemons et al. (2013); Groeneveld et al. (2015); Muramoto et } \\
\text { al. (2015); Skriba \& Havlicek (2018); Souza et al. (2018); } \\
\text { Hudson et al. (2019) }\end{array}$ \\
\hline Aspirin & $\begin{array}{l}\text { Day et al. (2004a); Day et al. (2004b); West \& Went (2008); } \\
\text { Ng et al. (2009); Banas et al. (2012); Banas et al. (2014); } \\
\text { Sundar \& Rowell (2014); Sundar \& Rowell (2015) }\end{array}$ \\
\hline Barbital & Day et al. (2004a); Day et al. (2004b); \\
\hline $\begin{array}{l}\text { Benzodiazepines: } \\
\text { Diazepam, flunitrazepam, lorazepam [3-O- } \\
\text { glucuronide], nitrazepam }\end{array}$ & $\begin{array}{l}\text { Day et al. (2004a); Day et al. (2004b); Goucher et al. (2009); } \\
\text { Ng et al. (2009); Moule et al. (2017) }\end{array}$ \\
\hline $\begin{array}{l}\text { Caffeine [paraxanthine. theobromine, } \\
\text { theophylline] }\end{array}$ & $\begin{array}{l}\text { Day et al. (2004a); Day et al. (2004b); West \& Went (2008); } \\
\text { Ng et al. (2009); Bradshaw et al. (2012); Clemons et al. (2013); } \\
\text { Kuwayama et al. (2013); Sundar \& Rowell (2014); Sundar \& } \\
\text { Rowell (2015); Watkinson (2018) }\end{array}$ \\
\hline
\end{tabular}




\begin{tabular}{|c|c|}
\hline Chlorpheniramine & Kuwayama et al. (2014) \\
\hline $\begin{array}{l}\text { Cocaine [benzoylecgonine, } \\
\text { methylecgonine, ecgonine methyl ester, } \\
\text { norcocaine] }\end{array}$ & $\begin{array}{l}\text { Day et al. (2004a); Day et al. (2004b); Hazarika et al. (2008); } \\
\text { Ng et al. (2009); West \& Went (2009); Hazarika et al. (2010); } \\
\text { Clemons et al. (2013); Li et al. (2013); Bradshaw \& Francese } \\
\text { (2014b); Sundar \& Rowell (2014); Bailey et al. (2015); } \\
\text { Groeneveld et al. (2015); Muramoto et al. (2015); Sundar \& } \\
\text { Rowell (2015); van der Heide et al. (2015); Yang et al. (2015); } \\
\text { Bradshaw et al. (2017); Costa et al. (2017); Ismail (2018); } \\
\text { Lauzon and Chaurand (2018); Skriba \& Havlicek (2018); Costa } \\
\text { et al. (2019b); Fowble and Musah (2019); Hudson et al. (2019) }\end{array}$ \\
\hline 4-hydroxybutanoic acid (GHB) & West \& Went (2008); Ricci \& Kazarian (2010) \\
\hline Ibuprofen & $\begin{array}{l}\text { Grant et al. (2005); Ricci et al. (2006); West \& Went (2008); } \\
\text { Kuwayama et al. (2014) }\end{array}$ \\
\hline Ketamine & West \& Went (2009) \\
\hline Mephedrone [nor-mephedrone] & Czerwinska et al. (2020) \\
\hline Nicotine [cotinine] & $\begin{array}{l}\text { Leggett et al. (2007); Hazarika et al. (2009); Benton et al. } \\
\text { (2010a); Benton et al. (2010b); Boddis \& Russell (2011); Lim et } \\
\text { al. (2013); Groeneveld et al. (2015); Yang et al. (2015) }\end{array}$ \\
\hline $\begin{array}{l}\text { Opiates: } \\
\text { Codeine, dihydrocodeine, heroin } \\
\text { (diacetylmorphine) [morphine, 6- } \\
\text { monoacetylmorphine], methadone [2- } \\
\text { ethylidene-1,5-dimethyl-3,3- } \\
\text { diphenylpyrrolidine (EDDP)], noscapine }\end{array}$ & $\begin{array}{l}\text { Day et al. (2004a); Day et al. (2004b); Ricci et al. (2006); } \\
\text { Hazarika et al. (2008); Jacob et al. (2008); West \& Went } \\
\text { (2008); Rowell et al. (2009); Hazarika et al. (2010); Lim et al. } \\
\text { (2013); Kuwayama et al. (2014); Sundar \& Rowell (2014); } \\
\text { Groeneveld et al. (2015); Muramoto et al. (2015); Sundar \& } \\
\text { Rowell (2015); Bailey et al. (2016); Ismail (2018); Lauzon \& } \\
\text { Chaurand (2018); Skriba \& Havlicek (2018); Hudson et al. } \\
\text { (2019) }\end{array}$ \\
\hline Paracetamol & $\begin{array}{l}\text { Day et al. (2004a); Day et al. (2004b); Ricci et al. (2006); West } \\
\text { \& Went (2008); Ng et al. (2009); Sundar \& Rowell (2014); } \\
\text { Sundar \& Rowell (2015) }\end{array}$ \\
\hline Procaine & Kaplan-Sandquist et al. (2014); Kaplan-Sandquist et al. (2015) \\
\hline Quetiapine (antipsychotic drug) & Costa et al. (2019) \\
\hline $\begin{array}{l}\text { Sympathomimetics: } \\
\text { Methylephedrine [ephedrine], } \\
\text { pseudoephedrine }\end{array}$ & $\begin{array}{l}\text { Kaplan-Sandquist et al. (2014); Kuwayama et al. (2014); } \\
\text { Kaplan-Sandquist et al. (2015); Fowble and Musah (2019) }\end{array}$ \\
\hline Terbinafine (antifungal drug) & Lim and Seviour (2012) \\
\hline $\begin{array}{l}\text { 9-Tetrahydrocannabinol (THC) [11-nor-9- } \\
\text { carboxy- } \Delta^{9} \text {-tetrahydrocannabinol, } \\
\text { tetrahydrocannabinolic acid] }\end{array}$ & $\begin{array}{l}\text { Hazarika et al. (2008); Ifa et al. (2008); Groeneveld et al. } \\
\text { (2015); Lauzon and Chaurand (2018); Hudson et al. (2019) }\end{array}$ \\
\hline
\end{tabular}


Table 3: Summary of cosmetic and personal products that have been detected within fingermarks

\begin{tabular}{|l|l|}
\hline $\begin{array}{l}\text { Cosmetic/personal product or } \\
\text { constituent }\end{array}$ & Reference \\
\hline Bug spray & Hinners et al. (2018) \\
\hline Condom lubricants & Bradshaw et al. (2011, 2012, 2013a), Mirabelli et al. (2013) \\
\hline $\begin{array}{l}\text { Cosmetics e.g. foundation } \\
\text { hand/body lotion, body butter, } \\
\text { serum cream and their constituents } \\
\text { (e.g. dimethylbenzylammonium and } \\
\text { dimethyldioctadecylammonium } \\
\text { ions) }\end{array}$ & $\begin{array}{l}\text { Kazarian (2010); Bradshaw et al. (2013b); Lauzon \& Chaurand } \\
\text { (2018); Yang et al. (2019) }\end{array}$ \\
\hline $\begin{array}{l}\text { Hand sanitisers, antibacterial } \\
\text { wipes/detergents }\end{array}$ & $\begin{array}{l}\text { Bradshaw et al. (2011); Bradshaw et al. (2013b); Bradshaw \& } \\
\text { Francese (2014b); Bradshaw et al. (2017), Chadwick et al. (2017) }\end{array}$ \\
\hline $\begin{array}{l}\text { Hair products } \\
\text { Sunscreen }\end{array}$ & $\begin{array}{l}\text { Wolstenholme et al. (2009); Bradshaw et al. (2013b) } \\
\text { (2019) }\end{array}$ \\
\hline
\end{tabular}

Table 4: Summary of explosive and gunshot residue traces that have been detected within fingermarks

\begin{tabular}{|c|c|}
\hline Explosive / Gunshot residue trace & Reference \\
\hline Ammonium nitrate & $\begin{array}{l}\text { Emmons et al. (2009); Mou and Rabalais (2009); Ng et al. } \\
\text { (2009); Tripathi et al. (2011); Fernandez de la Ossa et al. (2014) }\end{array}$ \\
\hline C4 & Emmons et al. (2009); Banas et al. (2014) \\
\hline Chlorate and perchlorate & Gilchrist et al. (2012); Love et al. (2013) \\
\hline DNT (2,4-dinitrotoluene) & $\begin{array}{l}\text { Abedlhamid et al. (2011); Lucena et al. (2013); Malka et al. } \\
\text { (2013) }\end{array}$ \\
\hline $\begin{array}{l}\text { Gunshot residues e.g. barium, cyanate, } \\
\text { lead, nitrite, nitrate, strontium }\end{array}$ & $\begin{array}{l}\text { Szynkowska et al. (2010) ; Gilchrist et al. (2012); Love et al. } \\
\text { (2013); Pluháček et al. (2018) }\end{array}$ \\
\hline $\begin{array}{l}\text { HMX (cyclotetramethylene- } \\
\text { tetranitramine (High Melting eXplosive)) }\end{array}$ & Emmons et al. (2009); Tripathi et al. (2011); Rowell et al. (2012) \\
\hline
\end{tabular}




\begin{tabular}{|c|c|}
\hline MNT (mononitrotoluene) & Abedlhamid et al. (2011) \\
\hline Nitroglycerin (TNG) & Rowell et al. (2012) \\
\hline PETN (pentaerythritol tetranitrate) & $\begin{array}{l}\text { Emmons et al. (2009); Ng et al. (2009); Tripathi et al. (2011); } \\
\text { Banas et al. (2012); Rowell et al. (2012); King et al. (2013); } \\
\text { Lucena et al. (2013); Banas et al. (2014); }\end{array}$ \\
\hline Potassium nitrate & Malka et al. (2013); Figueroa et al. (2017) \\
\hline Pyrodex & $\begin{array}{l}\text { Gilchrist et al. (2012); Love et al. (2013); Gallidabino et al. } \\
\text { (2019) }\end{array}$ \\
\hline $\begin{array}{l}\text { RDX (1,3,5-trinitro-1,3,5-triazine (Royal } \\
\text { Demolition eXplosive) }\end{array}$ & $\begin{array}{l}\text { Ifa et al. (2008); Chen et al. (2009); Emmons et al. (2009); } \\
\text { Tripathi et al. (2011); Banas et al. (2012); Rowell et al. (2012); } \\
\text { King et al. (2013); Lucena et al. (2013); Kaplan-Sandquist et al. } \\
\text { (2014); Kaplan-Sandquist et al. (2015); Fowble and Musah } \\
\text { (2019) }\end{array}$ \\
\hline TATP (triacetone triperoxide) & Rowell et al. (2012) \\
\hline $\begin{array}{l}\text { Tetryl ( } N \text {-methyl- } N-(2,4,6- \\
\text { trinitrophenyl)nitroaniline) }\end{array}$ & Rowell et al. (2012) \\
\hline Trinitrobenzene & Mou and Rabalais (2009) \\
\hline TNT (2,4,6-Trinitrotoluene) & $\begin{array}{l}\text { Mou and Rabalais (2009); Abedlhamid et al. (2011); Banas et al. } \\
\text { (2012); Rowell et al. (2012); King et al. (2013); Lucena et al. } \\
\text { (2013); Banas et al. (2014); Kaplan-Sandquist et al. (2014); } \\
\text { Kaplan-Sandquist et al. (2015) }\end{array}$ \\
\hline
\end{tabular}

\section{POST-DEPOSITION CHANGES IN FINGERMARK CHEMISTRY}

The previous sections describe the composition of the material that is deposited in the fingermark at the point of initial contact. It is recognised that this composition will almost immediately begin to change. Interactions between the fingermark, the environment and the surface occur over the period of time between deposition and recovery through a series of interactions that can be defined by the 'Triangle of Interaction' (Baniuk,1990; Sears et al., 2012). As a consequence, it is likely that several of the compounds initially deposited in the fingermark, depending on how chemically labile and susceptible they are, will no longer be present by the time the item it has been deposited on is treated in a laboratory.

Several studies have explored the influence of different environmental factors (light, ultraviolet radiation, heat, humidity and time) on the changes in the chemical composition of a fingermark, and some have proceeded to investigate the impact of those chemical changes on its subsequent 
development. Although research has been conducted into the effect of more extreme environments such as chemical decontamination (Wilkinson, 2005; Zuidberg et al., 2014), elevated temperatures (Richmond-Aylor et al., 2007) and exposure to ionising radiation (Hoile et al., 2010), those studies examining variables across ranges typical of a specific ambient environment are most relevant for the vast majority of situations encountered in casework.

A summary of published research into compositional changes during fingermark ageing was produced by Cadd et. al (2015), and there have been several subsequent publications that build on knowledge in this area. The changes in the sebaceous constituents of fingermarks appear to have received more attention (Olsen, 1987; Wolstenholme et al., 2009; Weyermann et al., 2011; Fritz et al.., 2013; Girod et al., 2015; Muramoto et al., 2015; Frick et al., 2016; Reed et al.., 2016; Szaboova et al., 2017; O'Neill \& Lee, 2018; Kim et al., 2020; Dorakumbura et al., 2020), possibly because these have been shown to be more affected by environmental exposure. These constituents also ionise easily, facilitating their analysis by mass spectrometry. Olsen (1987) found that exposing fingermarks to temperatures above ambient and observing the corresponding thin layer chromatograms indicated that free fatty acids, cholesterol and squalene decreased to levels below their limits of detection over the period of hours/days in that order. Several other researchers have observed a decrease in the level of squalene, which is initially abundant in sebaceous sweat. Archer et al. (2005) observed that loss of squalene was more rapid when fingermarks were exposed to light compared to storage in the dark, suggesting a photodegradation mechanism. In a subsequent study Mountfort et al. (2007) proposed a progressive oxidation process from the squalene, squalene epoxide and squalene monohydroperoxide present at the time of deposition to the final product squalene pentahydroperoxide, with squalene found to be absent after 7 days.

Ultraviolet radiation has been observed to have a greater impact on certain fingermark constituents than visible light. It has been shown (Dennis \& Shibamoto, 1989; Yeo \& Sibamoto, 1992) that squalene will decompose to formaldehyde and malonadehyde on exposure to ultraviolet radiation and that this degradation is more rapid for shorter wavelengths. Goode et. al. (1979) observed that exposure to ultraviolet radiation was detrimental to subsequent fingermark visualisation using radioactive bromine and this may be associated with a ultraviolet-induced breakdown of squalene, thought to be the principal target for this process. This was consistent with previous observations by Gray (1978) indicating ultraviolet radiation had most impact on unsaturated compounds and had a detrimental effect on their development using iodine fuming.

On the whole eccrine constituents appear less affected by light or ultraviolet radiation although it has been found (De Paouli et al., 2010) that lactic acid can degrade by a photochemical reaction when exposed to artificial sunlight. Urea and amino acids were found to be unaffected by the same exposure conditions.

Cuthbertson \& Morris (1972) monitored changes in the concentration of urea and chloride in fingermarks over a period of approximately 8 months. They found that although the chloride concentration appeared to be constant over this period, there did seem to be a significant reduction in urea.

\section{UTILISATION OF CHEMICAL CHANGES IN FINGERMARKS FOR DATING PURPOSES}


It has been proposed by several groups of researchers that the changes that occur in fingermark chemistry over time may be useful in establishing a timeline for its deposition.

The focus of these studies has primarily been the sebaceous constituents of fingermarks, although in operational casework these would generally be expected to be less abundant than eccrine sweat. Weyermann et al. (2011) used GC-MS to consider whether the use of squalene/cholesterol ratios within fingermarks could be used as a potential means of dating and this approach was subsequently refined further using the same technique by Koenig et al. (2011) with the addition of the wax ester content into the calculations. Szaboova et al. (2017) employed GC-MS to also propose the use of squalene content, in this case in a ratio with pentadecanoic acid, as a means of dating fingermarks. Girod et al. (2016) adopted a more holistic approach using principal component analysis on the lipid fraction in the fingermark but ultimately concluded that other factors such as substrate and intradonor variability had a significant effect on results and made accurate dating by this method difficult.

Other researchers (Muramoto et al., 2015) employed Secondary lon Mass Spectrometry (SIMS) imaging and used the rate of diffusion of sebaceous constituents on a silicon water surface to give an approximate time since deposition. However, later results obtained by O'Neill et al. (2018) using Matrix Assisted Laser Desorption Ionisation Mass Spectrometry Imaging (MALDI MSI) showed a strong influence of the substrate on diffusion rates, making the use of such models problematic.

Wolstenholme et al. (2009) were the first authors to employ MALDI in Profiling and Imaging modes (MALDI MSP and MALDI MSI) to closely monitor oleic acid and its degradation products. Here, the intention was to pinpoint age on the basis of the relative abundance changes of inter-relating species. MALDI MSI has also been used to visualise the reaction products formed between atmospheric ozone and the triglycerides in sebaceous sweat directly on the ridge pattern (Pleik et al. 2018, Hinners et al. 2020). It has been suggested that characteristic reaction products are formed that can be tracked over time and seem relatively independent of fingermark donor across the small pool of donors tested to date.

A review of chemical mass spectrometry imaging methods for fingermark imaging has recently been conducted by Francese and Bradshaw (2020). This highlights the challenge and complexity of age determination studies; it is extremely difficult to address all the interrelated factors influencing the correct determination/prediction of the age of a mark in a single study. In addition, the use of groomed (sebum-rich) fingermarks in many such studies is an unrealistic representation of crime scene marks and does not provide a true evaluation of method sensitivity.

The eccrine constituents of fingermarks have also been evaluated for dating purposes. It has been proposed (van Dam et al., 2014; van Dam et al., 2016) that the fluorescence of the amino acid tryptophan and its progressive breakdown to its fluorescent derivatives indoleacetic acid, harman, norharman and xanthurenic acid can be used as a means of estimating time since deposition. All of these substances have slightly different emission and absorption spectra. As tryptophan breaks down and the ratio between the original amino acid and its derivatives changes there is a shift in the position of the combined fluorescence emission peak and the authors propose this can be related to the age of the fingermark. 
Following from the first fingermark protein maps generated by Ferguson et al. (2012) and Patel et al. (2015), via non-destructive MALDI MS based approaches, a destructive proteomic approach to fingermark dating had been explored by Oonk et al. (2018) via Liquid Chromatography tandem Mass Spectrometry. These authors investigated whether any of the proteins identified exhibited a response to ongoing environmental exposure that could be used in fingermark age estimation. It was proposed that dermcidin (the abundance of which decreased over time) and four keratin proteins (the abundance of which increased with time) offered potential for development of an ageing model. However, validation of any such model necessitates use of natural marks, multiple donors, a range of environmental conditions and surfaces of deposition individually and in combination.

Another chemical change that is being evaluated for dating purposes is racemisation of amino acids (van Helmond et al., 2020). In this approach the progressive, naturally occurring conversion of the Lstereoisomer of the amino acid into the D-stereoisomer was explored for a series of amino acids (histidine, serine, threonine, alanine, proline, methionine and valine). Of these, the $\mathrm{D} / \mathrm{L}$-serine ratio appeared to exhibit a potentially significant change over time although it is recognised that the effect of many other environmental factors that may affect results such as $\mathrm{pH}$ and temperature would need further study.

The corresponding physical changes that occur in fingermarks during ageing have been studied by several researchers (Thomas \& Reynoldson, 1975; Moret et al., 2015; Dorakumbura et al., 2016; De Alcarez-Fossoul et al., 2018.) and in some cases have been proposed as aids to fingermark dating although more detailed consideration of this is beyond the scope of this review.

\section{UTILISATION OF FINGERMARK CHEMISTRY IN MARK ENHANCEMENT}

\subsection{Eccrine sweat}

Because eccrine glands are the only glands present on the surface of the palm and the fingers, it is anticipated that the major component of any latent mark will be eccrine sweat. As a consequence, the majority of processes in widespread use tend to utilise the chemicals found in this component. The ways in which some of the principal constituents of eccrine sweat have been utilised in fingermark enhancement are outlined below.

\subsubsection{Water}

Water is the principal solvent for the other chemicals found within eccrine sweat. Although eccrine sweat contains $98 \%$ water, the content deposited in a latent fingermark has been a subject of recent debate with Kent (2016) suggesting it may be as low as $20 \%$ and subsequent studies (Keisar et al., 2019 ) indicating that a range of $20-70 \%$ is realistic.

Water is utilised by fingermark visualisation processes in a variety of ways. It is one of the substances that promotes adhesion of particles to the fingermark during the application of powders, and the effectiveness of many powders will decrease as the mark dries out and water is lost. For this reason, the practice of 'huffing' (re-humidifying the fingermark with warm, humid air) is sometimes used to increase fingermark recovery when powdering older marks (Montgomery et al., 2012). 
Water is also essential to achieving optimum results using the cyanoacrylate (superglue) fuming process. Water can act as a weak base to initiate polymerisation of cyanoacrylate monomer vapour to form polycyanoacrylate on the fingermark ridges. Lewis et al. (2001) demonstrated that cyanoacrylate fuming of older, eccrine marks where water content had been lost by evaporation resulted in lower quality fingermarks. Many commercial fuming chambers incorporate a humification stage to re-introduce water to the fingermark ridges prior to fuming. Paine et al. (2011) demonstrated that a humidity range of between 75 and $90 \%$ was required for optimum enhancement of both eccrine and sebaceous marks. It was also seen that the humidity level used influenced the morphology of the polycyanoacrylate deposit formed. Alternative approaches such as pre-treatment with acetic acid, ammonia (Wargacki et al., 2008) and methylamine (McLaren et al., 2010) have been proposed to improve the quality of developed marks in situations where deposits have dried out and water has been lost.

Water has been shown to enhance the results obtained from iodine fuming (Almog, Sasson \& Anati, 1979). Almog proposed two interaction mechanisms that may bind the iodine into the fingermark, a dipole-induced dipole interaction between iodine and water molecules, and the partial transfer of electrons from the water (Lewis base) to the iodine (Lewis acid) to produce a loosely bound charge transfer complex. The loss of water, as marks dry out, may be a contributing factor to the reduction observed in the effectiveness of iodine fuming in the development of fingermarks more than a few days old (Goode \& Morris, 1983).

\subsubsection{Amino acids}

Amino acids are the most abundant constituents of eccrine sweat. They are also the most important chemical target for development of fingermarks on porous surfaces such as paper. Because amino acids are larger molecules than urea and sodium chloride and can also interact with the cellulose chains in the substrate (Spindler et al., 2011; Spindler et al., 2015), they do not generally migrate from the site of initial deposition unless exposed to high humidity or fully immersed in water. Fingermarks on paper can therefore be detected using amino acid reagents many years after deposition unless exposed to such adverse conditions (Bleay et al., 2019).

A wide range of amino acid reagents have been used for fingermark visualisation, some adapted from existing colorimetric tests and others synthesised specifically for fingermark applications. The first reagent proposed for fingermark development was ninhydrin (Oden \& von Hofsten, 1954). The reaction of ninhydrin with a range of amine-containing substances to form the characteristic Ruhemann's Purple product had been noted as early as 1910 (Ruhemann, 1910). Oden and von Hofsten recognised that there were sufficient amino acids in fingermarks to make ninhydrin useful for fingermark visualisation. The initial formulation has been subsequently refined to increase sensitivity and reduce flammability (Morris et al., 1973) and to minimise the impact on other forensic analyses such as document examination. The reaction mechanism between amino acids and ninhydrin has been extensively studied, for example by Joullié et al. (1991), and in most cases is expected to proceed to the characteristic purple reaction product. However, the reaction rate may vary for different amino acids and in some cases the reaction may stop at different coloured intermediate compounds. The reaction rate (and the effectiveness of the process for fingermark development) can be accelerated by the addition of a controlled amount of water and elevated 
temperature (Linde, 1975). Humidified ovens are generally used for development to provide these conditions in a controlled manner.

A range of other amino acid reagents have been considered for fingermark development with the objective of improving on the sensitivity achieved with ninhydrin. It was recognised that the use of a reagent giving a fluorescent reaction product may improve the limit of detection and the first of these compounds to be investigated were fluorescamine and o-phthlaldehyde (Lee \& Attard, 1979). Although shown to give potential improvements in sensitivity over ninhydrin, the practicality of these reagents is limited by the use of optical brighteners in modern papers which fluoresce under the same irradiation conditions as the developed fingermark and obscure it.

The development of lasers and high intensity light sources with output in the visible region of the spectrum made the use of other fluorescent amino acid reagents feasible, including NBD chloride (4chloro-7-nitrobenzofurazan) (Warrener et al., 1983). It was also observed that marks developed using ninhydrin could be post-treated with salts of zinc and cadmium (Lennard et al., 1987) to produce a fluorescent product and increase the number of marks detected.

Modifications of ninhydrin have been another focus of research, with many analogues produced and evaluated including 5-methylthioninhydrin (Almog et al., 1992), 5-methoxyninhydrin (Lennard et al., 1986) and benzo[f]ninhydrin (Almog et al., 2000). Of all of these analogues, 5-methylthioninhydrin (5MTN) has proved most useful.

The introduction of 1,8-diazafluoren-9-one (DFO) in the early 1990s (Grigg et al., 1990) provided an amino acid reagent that was both more sensitive than ninhydrin and also provided a fluorescent reaction product. DFO became recognised as the most effective amino acid reagent for fingermark visualisation until 1,2-indandione was later proposed for this purpose (Hauze et al., 1998). The results initially obtained using 1,2-indandione were variable, but the incorporation of zinc chloride into the formulation produced a reaction that was more consistent (Spindler et al., 2009) and it is now generally recognised that 1,2-indandione formulations with zinc chloride are the most effective amino acid reagents currently available.

Attention has also been given to 'dual action' reagents where the developed marks are both coloured and fluorescent, including genipin (Almog et al., 2004) and 5MTN with additions of zinc chloride (Almog et al., 2008). Although such reagents may have niche applications, they have been found to generally be less effective than ninhydrin in developing coloured marks, and less effective than DFO or 1,2-indandione in developing fluorescent marks (Porpiglia et al., 2012).

It should also be noted that the reagent 4-dimethylaminocinnemaldehyde (DMAC) also reacts with amino acids when applied to fingermarks as a vapour (Brennan et al., 1995) and this has been proposed as a method for development of fingermarks on thermal papers without removing the text.

The reaction between the amino acid and the reagent produces a product that is either coloured (e.g. ninhydrin), fluorescent (e.g. DFO, 1,2 indandione), or both (e.g. genipin, 5-MTN). In some cases the reaction product may be independent of the amino acid contributing to the reaction (e.g. the Ruhemann's purple for ninhydrin) and in others the reaction product retains some character of the 
individual amino acid (e.g. genipin). Of all of the reagents investigated the most widely used are ninhydrin, 1,2 indandione and DFO.

The application of a single amino acid reagent does not result in exhaustion of all amino acids present. Several studies (Salama et al., 2007; McMullen \& Beaudoin, 2013; Marriott et al., 2014; and Bleay et al., 2019) and operational experience have demonstrated that sequential use of amino acid reagents (ninhydrin after DFO or 1,2 indandione) will develop additional marks. The progressive consumption of amino acids during sequential treatment has been studied using mass spectrometry (Mangle, Xu \& de Puit, 2015) which confirms that a significant proportion of the amino acid fraction remains available for reaction if a second reagent is applied.

Amino acids may also contribute to the detection of latent fingermarks by fluorescence examination. Some naturally occurring amino acids in eccrine sweat (tyrosine, tryptophan and phenylalanine) are fluorescent (Teale \& Webber, 1957) and this may enable fingermarks to be detected during examination with high intensity light sources. However, the fluorescence contribution from amino acids is likely to be low in comparison with other contaminants that may be present. The potential use of the change in fluorescence spectra associated with progressive degradation of tryptophan as a method to date fingermarks has already been discussed in this review.

Finally, it has been suggested (Wargacki et al., 2007) that the carboxylate functional group of the amino acid alanine may be another contributor to the initiation of cyanoacrylate polymerisation in the superglue fuming process.

\subsubsection{Urea}

Urea is relatively abundant in eccrine sweat but there have been few development techniques that have utilised it. A formulation of DMAC in solution (Goode \& Morris, 1983) produced fingermark development without the need for heating. The reaction between DMAC and urea in an acidic environment formed a magenta-coloured Schiff base. The process was relatively quick and did not require specialist equipment such as ovens, but operationally DMAC was ineffective because many marks developed on older exhibits were diffuse without clear ridge detail. The small size of the urea molecule means that it can migrate more easily from the point of deposition, contributing to this issue. The process is no longer used.

\subsubsection{Sodium chloride}

The sodium chloride content of fingermarks can be utilised for their development by using the silver nitrate process. When sodium chloride is exposed to a solution of silver nitrate, a reaction can occur between the chloride constituent and silver nitrate to form insoluble silver chloride. Silver chloride is a light sensitive compound and on subsequent exposure to light the silver is reduced to its metallic form, darkening the fingermark sufficiently for it to be seen.

Cuthbertson (1969) used the silver nitrate process extensively in studies of the chloride content in latent fingermarks and it is still occasionally used in casework. The main limitation is that chloride ions are small and relatively mobile, and rapid diffusion of ridge detail can occur on exposure to high humidity environments. 
Sodium chloride in fingermarks may also act as an initiator of corrosion on certain metal surfaces and several methods have been proposed that visualise fingermarks by detecting the corrosion signatures that they have produced (Williams et al., 2001; Bond, 2008; Wightman \& O'Connor, 2011).

The sodium and potassium ions present in eccrine sweat have also been successfully used as a means of visualising fingermarks on both porous and non-porous surfaces (Bailey et al., 2010; Bailey et al., 2013). Secondary lon Mass Spectrometry (SIMS) has a spot size of $<1 \mu \mathrm{m}$, providing high resolution images of fingermarks sufficient to reveal the pore structure. The technique has been reported to image fingermarks deposited on paper, metal and plastic surfaces before or after development with cyanoacrylate (Bailey et al., 2013). A high resolution map of potassium ion distribution obtained by SIMS is shown in Figure 3.

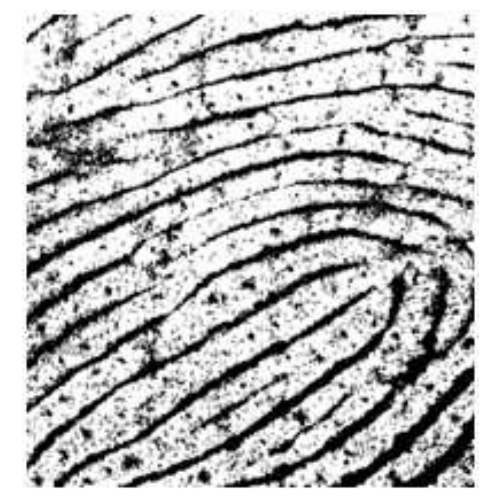

Figure 3. Chemical Imaging of a fingermark: Time of Flight (TOF) SIMS image of potassium ( $\left.K^{+}\right)$in a fingerprint deposited on brass, showing third level detail.

\subsubsection{Sodium lactate}

Studies conducted by Wargacki et al. (2007) indicated that the lactate in constituent of fingermarks was another initiator of the polymerisation reaction during cyanoacrylate fuming and that ultraviolet degradation of lactate may contribute to the drop in effectiveness of this process on older fingermarks (Wargacki et al., 2008)

\subsubsection{Proteins and peptides}

In 2009 Drapel et al. demonstrated the feasibility of detecting keratin 1, keratin 10 and cathepsin-D in eccrine sweat using antibody tests but this has not subsequently resulted in practical methods. An immunolabelling method using tagged antibodies has also been developed as a developer targeting dermicidin, (van Dam et al., 2013a, 2013b) and this is closer to practical implementation. The distribution of dermicidin in fingermarks can also be mapped directly using analytical techniques such as MALDI MSI (Francese, 2015), as illustrated in Figure 1.

Although it has been shown that there are diverse methods that target different eccrine sweat constituents for fingermark enhancement, there are still many constituents of eccrine sweat (e.g. the carboxylic acid functionality of amino acids, vitamins and lactic, uric and pyruvic acids) that are not specifically utilised. However, such substances are typically less abundant and less stable, hence there may be limited benefit in basing novel development reagents on them. 


\subsection{Sebaceous secretions}

Although expected to be less abundant than the eccrine component, there will generally be some sebaceous material present in fingermarks and several reagents have been employed to react with constituents of sebum.

The first reagent proposed primarily for reaction with the fats in fingermarks was osmium tetroxide (Mitchell, 1920) which reacts across the unsaturated carbon double bonds present in several of the compounds present. However, the toxicity of this reagent means that it is no longer considered for operational use.

\subsubsection{Squalene}

Squalene is one of the most abundant sebum constituents, although it is lost relatively quickly from the fingermark. It is thought to be one of the principal targets for the iodine fuming process, and the rapid loss of squalene is another reason proposed for the poorer performance of iodine fuming on older fingermarks. One mode of interaction may be a reaction across the double bonds (PopolanVaida et al., 2014) but this may not account for the intense brown colour observed when spots of squalene are exposed to iodine vapour and simple absorption of iodine into the fats may also be a factor. Oil Red $O$ has also been shown to strongly stain squalene (Salama et al., 2007).

\subsubsection{Cholesterol}

Cholesterol is another sebaceous constituent that is heavily stained by Oil Red O (Salama et al., 2007) and has also been shown to be strongly stained by basic violet 3 and basic violet 2 (Garrett \& Bleay, 2013). In the case of basic violet 3 and basic violet 2 the stained cholesterol test spots also exhibited strong fluorescence.

\subsubsection{Fatty acids}

The range of fatty acids present in sebum have been shown to vary in their interactions with the reagents used for fingermark enhancement. Salama et al. (2007) found that Oil Red O produced strong staining on palmitic, stearic, and to a lesser extent myristic acids, but did not significantly stain palmitoleic or oleic acids. Garrett \& Bleay (2013) observed strong staining of hexanoic acid by an ethanol-based solvent black 3 formulation, and of decanoic, dodecanoic, eicosanoic acids by a 1methoxy-2-propanol-based solvent black 3 formulation. Basic violet 3 was seen to strongly stain docosanoic acid (Garrett \& Bleay, 2013).

Oleic acid has also been proposed as a substance that can be used in printing a test strip for quality control testing of the physical developer process (Kupferschmid et al., 2010).

\subsubsection{Triglycerides}

Some of the triglycerides present in fingermarks may also be stained by fingermark reagents. These include staining of tristearin by Oil Red O (Salama et al., 2007) and glyceryl tripalmitate and glyceryl tristearate by basic violet 3 . 
Other sebaceous substances exhibiting strong interactions with fingermark reagents include cholesterol palmitate (Salama et al., 2007), stained by Oil Red O, cholesteryl acetate (Garrett \& Bleay, 2013), stained by solvent black 3 and giving strong fluorescence with basic violet 3 , and cholesteryl benzoate (Garrett \& Bleay, 2013) which gave strong fluorescence with basic violet 3.

\subsubsection{Mass Spectrometry Imaging of sebaceous constituents}

The compounds found in sebaceous secretions can also be effectively used to produce images of fingermarks when chemical imaging by mass spectrometry is employed. Desorption Electrospray Ionisation Mass Spectrometry Imaging (DESI MSI) was the first technique to be used to generate molecular maps of sebaceous constituents (Ifa et al., 2008); MALDI MSI has subsequently been used to generate fingermark images of fatty acids, diacyl and triacylglyerols at sufficient spatial resolution (up to 100*100 $\mu \mathrm{m}$ ) for minutiae to be observed (Wolstenhome et al., 2009; Ferguson et al., 2013), though cutting edge instrumentation can image a mark with much higher lateral resolution (10* 10 $\mu \mathrm{m})$. Similarly, the literature reports the use of silver-assisted LDI (AgLDI) Imaging to generate fingermark images at similar resolutions (Lauzon et al.,2017).

Figure 4 presents an example of fingermark images generated by DESI, MALDI, and AgLDI MS Imaging.

MALDI MS used in imaging mode has been a particularly prolific technique in generating images of lipids and a non-exhaustive list is reported in Bailey et al. (2012) and Ferguson et al. (2013). In addition, Ferguson et al. (2013) report that the application of the dry-wet method of matrix deposition greatly improves the ridge pattern clarity continuity when generating lipid molecular images.
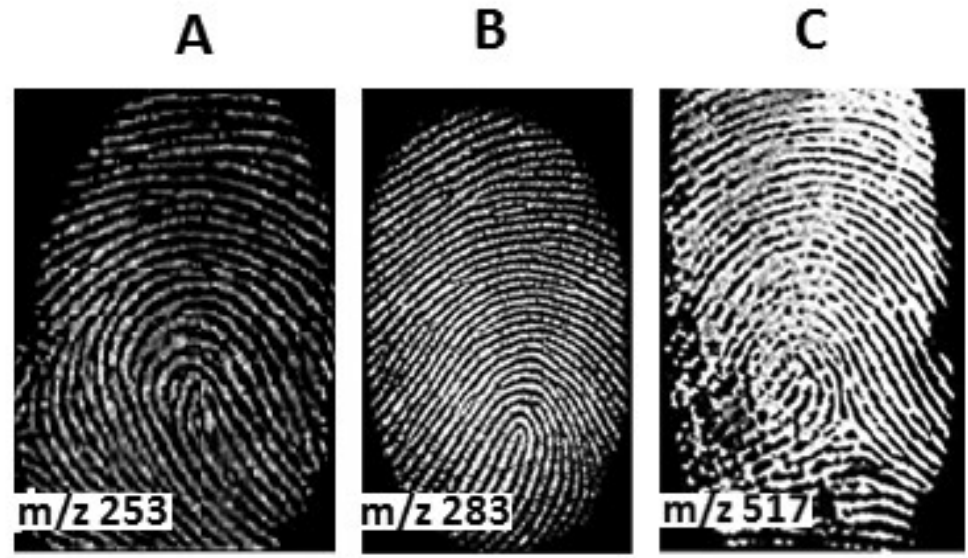

Figure 4 Chemical Imaging of fingermarks by mass spectrometry. (A) DESI MS image of cishexadecanenoic acid ( $m / z$ 253) from a groomed fingermark on glass (Ifa et al. Science 2008); (B) MALDI MS image of oleic acid (m/z 283) on an aluminium slide (Ferguson et al. 2013); (C) AgLDI image of squalene ( $\mathrm{m} / \mathrm{z} 517)$, in a latent fingermark on a lifting tape after dusting with green fluorescent powder and silver sputtering (Lauzon et al., 2017). Panel $A$ is from Ifa et al. (2008), with permission from The American Association for the Advancement of Science; panel $B$ is adapted from Ferguson et al. (2013) Journal of Mass Spectrometry with permission from John Wiley and Sons; panel $C$ is adapted from and Lauzon et al. (2017) with permission from John Wiley and Sons . 


\subsection{Sebaceous and eccrine emulsions}

There remain some fingermark development processes for which the mechanism of deposition is not fully understood, and combinations of eccrine and sebaceous constituents may be required for development to occur. The most researched of these processes is physical developer, the most effective process that can be used on porous surfaces that have been wetted. The most comprehensive studies into the constituents targeted by physical developer have been conducted by de la Hunty et al. (2015a, 2015b). These demonstrated that, when spots of sebaceous constituents (fatty acids, cholesterol and squalene) were treated with physical developer, only cholesterol was found to promote deposition of silver. However, when natural marks were treated with reagents containing solvents that dissolve fats, physical developer stopped working. It was shown that physical developer could selectively deposit at positions associated with the position of eccrine pores but did not develop purely eccrine fingermarks, possibly because of the water-based solutions used dissolving these constituents. A synergistic effect between eccrine and sebaceous constituents was proposed with a protective layer of non-water soluble material protecting eccrine constituents that promote deposition of silver from solution.

It is possible that a similar combination of sebaceous and eccrine material may be required for optimum performance of the powder suspensions process (Downham et al., 2017). Atherton (2013) used a number of analytical techniques (GC-MS, IC and FT-IR spectroscopy) to determine the amount of select eccrine (amino acids, inorganic ions) and sebaceous (fatty acids, squalene) constituents in latent fingermarks and whether there was any correlation with the quality of powder suspension development. However, no correlation was found for the constituents studied.

In some cases, the chemistry of the fingermark deposit is not necessarily important, but the fact that it differs from the substrate it has been placed upon is. The most significant process that works in this way is vacuum metal deposition, where it has been shown that the nucleation of the metal clusters that delineate the fingermark is controlled by surface characteristics. Monolayers of fatty constituents present on the surface in fingermarks can be detected by this method (Thomas, 1978) but eccrine constituents will also affect nucleation characteristics. The ability of vacuum metal deposition to detect a broad range of chemically different contaminants was demonstrated by Gaskell et al. (2013).

\subsection{Ingested substances and metabolites}

Although several studies of fingermark composition have shown that several metabolites can be detected by various analytical techniques, they have been under-utilised as a means of visualising fingermarks. A notable exception to this has been the work of Leggett et al. (2007) and Hazarika et al. (2009). Hazarika et al. used magnetic particles functionalised with anti-cotinine antibody and a fluorescent marker to selectively develop the fingermarks of smokers. The magnetic powders were applied in a standard powdering process and became bound to the cotinine antigen present in sweat. The process was capable of distinguishing between the fingermarks of smokers and non- 
smokers but the development was confined to the regions immediately around the eccrine pores and would not be a feasible method for developing continuous ridge detail.

In the following years, mass spectrometry proved to be a better approach for detecting and mapping metabolites in fingermarks due to both higher sensitivity and the opportunity to use an untargeted approach which does not require a priori knowledge of the molecular target (which is otherwise necessary for the selection of the appropriate antibody). In mass spectrometry, this application, detection and mapping of metabolites is again less likely to produce full images of fingermarks because these constituents tend to be concentrated around eccrine gland openings resulting in 'dotty', discontinuous ridges (unlike the more uniform distribution observed for sebaceous constituents). However, redistribution of such constituents may occur during contact (e.g. with the face) enabling continuous ridges to be imaged. Analysis of these species is more likely to generate contextual information about donor lifestyle (e.g. medication and diet).

In 2008-2009, the group of Jickells et al. (Jacob et al., 2008; Goucher et al., 2009) found that the prescription medications lorazepam and methadone, alongside their metabolites, could be detected in fingerprints using liquid chromatography mass spectrometry (LC-MS). The authors used creatinine normalisation to account for differences in biomass deposition, and the elimination profile of lorazepam could be observed through a pooled sample corresponding to set of fingerprints. Whilst the LC-MS approach provides excellent selectivity, a limitation is the destructive nature of the analysis and lack of spatial information.

In 2012 Bradshaw, Rao et al. demonstrated the ability to detect and map caffeine in a fingermark from a donor that had drunk coffee within 30 minutes prior to fingermark deposition, by using MALDI MSI. Caffeine was detected both intact and as fragments at $\mathrm{m} / \mathrm{z} 195.1$ and 138.0 respectively. This compound can be excreted in urine and in larger part in sweat (Kovacs et al. 1998), or metabolised into paraxantine, theophylline and theobromine. Whilst these metabolites were not detected in that instance, caffeine was truly an excretion product due to the study design which prevented any caffeine contamination of the fingertips. Subsequently, metabolites of caffeine have been observed in fingerprint residues using chromatographic approaches (Kuwayama et al., 2013; Watkinson, 2018) and have been found to relate to ingestion of caffeine.

Groeneveld et al. (2015) devised a MALDI base mass spectrometric method to detect and map a total of seventeen drugs of abuse and metabolites (including amphetamine, methylbenzoylecgonine (cocaine), diacetylmorphine (heroin), $\Delta$ 9-tetrahydrocannabinol (cannabis, $\triangle 9-\mathrm{THC}$ ), 3,4methylenedioxy-methamphetamine (ecstasy, MDMA), methylenedioxyamphetamine (MDA), ecgonine methyl ester (EME), benzoylecgonine (BZE), 6-acetylmorphine (6-MAM), morphine (MOR), 11-nor-9-carboxy-THC (THCA) and methadone) demonstrating that it was possible to detect both the parent drug and the corresponding metabolites within the same analysis from mocked up fingermarks. Findings from these studies showed that it was possible to obtain molecular images of drugs and metabolites in fingermarks for concentrations as little as $0.19 \mathrm{ng} . \mathrm{cm}^{-2}$ though some species exhibited a poorer ionisation efficiency and could be detected but not sufficiently to enable reconstruction of the fingermark ridge pattern.

One traditional limitation of mapping drugs or metabolites in fingermarks using mass spectrometry approaches is the time required per analysis (around 2-3 hours for a full fingermark), although advanced systems have demonstrated the potential to bring this down to 10 minutes. In 2015 
Bailey, Bradshaw et al. used DESI and MALDI in a profiling mode (non-imaging analysis) to rapidly detect cocaine and metabolites in the fingermarks of a small number $(n=4)$ of drug users in a timeframe of $\sim 2$ minutes per sample.

Costa et al. (2019b) developed a (destructive) methodology for detecting cocaine use from a whole fingermark using paper spray mass spectrometry and applied it to 239 fingermarks collected from patients attending a drug rehabilitation centre. It was possible to develop fingermark ridge detail with silver nitrate to reveal ridge details prior to mass spectrometry analysis. In general, there was good agreement between fingermark and oral fluid testing results for cocaine, with a $99 \%$ detection rate and $2.5 \%$ false positive rate. Paper spray mass spectrometry, as well as LC-MS has also been deployed for the detection of antipsychotic medications and their metabolites. The approach of Costa et al. (2019b) may be forensically useful for marks on paper recovered from scenes of crime, for example to profile a donor, or to show whether or not a donor was taking medication at the time of an offence. For the latter, more data on the elimination profile of antipsychotics is needed.

Although the detection of these metabolites in fingermarks using the reported mass spectrometry techniques is reliable, it is important to highlight that source level attribution is not enough to establish culpability or infer suspect activities. There remains the question of how metabolites (and contaminants) have ended up in someone's fingermarks. In fact, secondary transfer or environmental contamination could be alternative explanations.

To this end, Costa et al. (2017) Ismail et al. (2018), Costa et al. (2019a) and Jang et al. (2020) have explored significance of detecting cocaine and heroin in fingermarks. If hands can be washed prior to deposition of a fingermark, the detection of metabolites of drugs of abuse can be used to confirm that a drug has been used. In contrast, where hands are not washed (as in the case of crime scene fingermarks), fingermarks from drug use and drug contact could not be distinguished.

The increasing sensitivity of analytical techniques, and in particular of mass spectrometry means that caution must be taken when providing contextual information from the detection of both forensically interesting metabolites and contaminants in fingermarks.

\subsection{Skin cells}

The staining of epithelial cells by basic violet 3 is a long-recognised technique in histological staining, with the basic dye binding to negatively charged molecules on the surface of the cell and other materials such as polysaccharides that may be present. The fact that skin cells can be shed from the fingertip results in them being more abundant on substrates such as adhesive tapes, for which basic violet 3 is one of the recommended development processes.

There has also been an increased interest in the use of dyes for the detection of latent DNA and these have also been used to visualise the skin cells that may be shed in fingermarks (Haines et al., 2015; Kanokwongnuwut et al., 2018a; Kanokwongnuwut et al., 2018b; Kanokwongnuwut et al., 2019). In some circumstances there may be sufficient skin cells shed to be able to visualise the flow of the ridges. 


\subsection{Contaminants}

\subsubsection{Blood}

As discussed above, the number of contaminants that may be present on a fingertip during deposition of a mark is limitless, but for practical purposes the one that is of most interest is blood. Certainly the detection of blood is crucial in major crimes for a number of reasons. Blood indicates that a violent event has actually occurred and blood pattern analysis helps consequently to establish the dynamics of the crime. Blood is also a source of numerous other information about the individual that has shed it. First and foremost, DNA would establish the identity of the person (if matched to an available reference) or the provenance of blood other than human. Blood groups are also recoverable and this is valuable intelligence in the absence of a DNA match to narrow down the pool of suspects. Finally, blood may host metabolites indicating the presence of drugs and medications as well as potential disease biomarkers. Such contextual information could greatly inform investigations. MALDI MS Profiling and Imaging have been proposed as techniques elucidating much of the important intelligence mentioned above (Bradshaw et al., 2014a; McBean et al., 2015; Deininger et al., 2016; Park et al., 2019).

Like all other body fluids, blood has a complex chemistry. There are two main constituents, plasma and blood cells. Approximately $55 \%$ of the blood volume consists of plasma, which contains several substances that are also found in eccrine sweat including amino acids, urea, inorganic salts, metabolites and proteins. The remaining $45 \%$ is formed of red blood cells, white blood cells and platelets. All contain proteinaceous materials with the white blood cells providing a source of DNA, and the red blood cells containing the protein haemoglobin (which gives blood its red colour).

Different aspects of this chemistry can be utilised to enhance faint traces of blood. Because blood contains many amine containing compounds, all of the amino acid reagents are capable of developing fingermarks in this contaminant. (Moore et al., 2009; Bossers et al., 2011) The intensity of reaction observed with blood is typically greater than is seen with latent fingermarks because there are more amine-containing substances present within blood. The drawback with using amino acid reagents as a blood enhancement technique is the lack of specificity - latent fingermarks will be developed in addition to marks in blood, and other biological matrices such as semen also contain amino acids and proteins which could react with ninhydrin.

An approach that is often adopted when enhancing faint traces of blood is to target the protein constituents that are present in both the plasma and blood cell fractions. A range of acid dyes have been proposed for this purpose including acid black 1 (Godsell, 1963, Sears et al., 2000), acid violet 17 (Sears et al., 2001), acid violet 19 (Theeuwen et al., 1998), Coomassie Blue (Norkus and Noppinger, 1986) and acid yellow 7 (Sears et al., 2005). All of these dyes rely on the proteins being first fixed in some way, either dehydrated using heat or methanol, or precipitated using 5sulphosalicylic acid. The dye then selectively stains the proteins, and excess unbound dye molecules are removed with a wash solution. These dyes are all sensitive to faint traces of blood because there are many proteins present, however they have limitations in that they are not specific to blood and can give false positive reactions with a wide range of other protein-containing substances (Cadd et al., 2016). 
Greater specificity to blood can be obtained by the use of peroxidase reagents where the oxidation reaction from a colourless to a coloured form is catalysed by the haem molecule present in haemoglobin. The earliest chemicals proposed for this application (benzidine and o-tolidine) have been found to be carcinogenic and are no longer used. However, there are still a broad range of peroxidase reagents that have been adapted to enhancement of fingermarks in blood. These include 3, 3', 5, 5'-tetramethylbenzidine (TMB) (Holland et al., 1975; Garner et al., 1976), diaminobenzidine (Allman \& Pounds, 1989), leuco crystal violet (Bodziak, 1996), leuco malachite green (Cox, 1991) and fluorescein (Cheeseman \& DiMeo, 1995). The increased specificity of the reagents (targeting just the haem molecule within blood) means that they are less sensitive than the protein stains because there is less material available to react. Despite this increase in specificity, there are still some substances such as vegetable peroxidases and some metals (e.g. iron) that can produce a false positive reaction (Cox, 1991; Prestamo \& Manzano, 1993).

Further improvements in specificity for the detection of traces of blood have been achieved by the use of tagged nanoparticles (Frascione et al., 2012). In this approach a magnetic nanoparticle is tagged with antibodies specific to human blood. This results in a magnetic powder that can be applied to fingermarks using conventional magnetic applicators and allowed to incubate and bind with the blood antigens before excess powder is removed.

In terms of blood detection, while presumptive tests are quick and easy, they are prone to false positives due to their lack of target specificity. Confirmatory tests are possible remotely but they are destructive and do not disclose blood provenance unless serological tests are performed. MALDI MS imaging was proposed first in 2014 (Bradshaw et al.) as a much more reliable technique to ascertain the presence of blood due to the ability to specifically measure haemoglobin and haem in a single analysis.

In their work Bradshaw et al. demonstrated using MALDI MSI that: (i) it was possible to detect haemoglobin and haem on the ridge patterns of marks, even in a long depletion series where the blood was no longer visible (ii) that both molecules could be detected in fingermarks previously treated with ninhydrin and acid black 1 , and in a suspected crime scene bloodstain previously subjected to the Kastle-Meyer test and that (iii) haemoglobin protein sequences are sufficiently different to detect animal provenance within human, bovine and equine bloodstains that had been analysed.

Patel et al. (2015) adopted a proteomic approach yielding multiple blood specific protein signatures from haemoglobin and other proteins which enabled the discrimination of mixed provenance blood sources (a difficult task if mixed DNA required resolving). These signatures were then exploited by Deininger et al. (2017) to reconstruct molecular images of fingermarks deposited in blood. Kamanna et al. (2017) also used a proteomic approach concentrating on haemoglobins only to differentiate and map blood signatures from human and a range of Australian native mammals. Kennedy et al. (2020) have subsequently validated the proteomic approach developed by Patel et al. (2015) by MALDI MS on a total of 71 blind samples (stains and fingermarks) demonstrating that blood can be detected and discriminated from other biofluids and biofluid unrelated matrices. Semen markers were also detected in stains and in fingermarks, during this study. The technique was used to reliably determine the provenance when human, bovine, porcine and chicken samples were presented in a blind test. 


\subsubsection{Skin care products \& cosmetics}

A large class of possible contaminants is derived from day care products, including soaps, hand sanitisers, hair products and cosmetics. Many of these are either applied using the hands or applied to the hands so it is unsurprising that traces of them may be detected within fingermarks.

Chadwick et al. (2017) investigated the impact of the use of hand sanitisers on the subsequent effectiveness of fingermark enhancement processes. They found that alcohol-based sanitisers had no observable effects, however when non-alcoholic sanitisers were used an increase in the quality of developed marks was observed when amino acid reagents were used. This was attributed to the presence of benzalkonium chloride (alkyldimethylbenzyammonium chloride), the active ingredient in such sanitisers, as a contaminant in fingermarks.

At least two substances found in antibacterial wipes/gels, detergents and hair products have also been detected, identified and mapped using MALDI MSI (Bradshaw et al., 2011; Bradshaw et al., 2013). The alkyldimethylbenzyammonium chloride ion (as proposed by Chadwick et al. above) and the closely related dimethyldioctadecylammonium ion at $m / z 304.3$ and 550.6 respectively, are frequently detected and reported in many MALDI MSI based publications on fingermark analysis. They have a very good ionisation efficiency and as such very often yield high quality ridge detail when the technique is used in the imaging mode.

However, much analytical attention must be paid to these or any other substances if they are used to provide contextual information. For example, alkyldimethylbenzyammonium chloride has the same nominal $\mathrm{m} / \mathrm{z}$ as cocaine (304 Thomson units). As such there is a risk to either overlook the presence of cocaine or to claim it when the individual had simply performed a personal hygiene action. The use of tandem mass spectrometry is always recommended to confirm molecular identification and Bradshaw \& Francese (2014b) have suggested an identification approach that combines tandem mass spectrometry and imaging.

Hinners et al. (2018) have also employed MALDI MS Imaging to detect, visualise and source attribute active ingredients from insect sprays and sunscreens, as well as food oils, alcohols, and citrus fruits.

\subsubsection{Grease}

Another contaminant that can occasionally be of relevance in operational environments is 'grease'. A range of different oils and greases can be encountered, and the composition of the contamination will vary according to the whether the origin of the material is foodstuffs and cooking material, mechanical lubricants, or cosmetics and wash products. Gaskell et al. (2011) conducted a study of the effectiveness of a range of reagents on contaminants from 'kitchen', 'garage' and 'bathroom' environments. This found differences between the types of contaminant that were strongly developed by each of the reagents used. An iodine solution gave intense development of sugarcontaining substances such as cola, lager, cider, red wine, orange juice, ketchup and cough syrup, in addition to moisturiser, engine grease and Swarfega hand cleaner, although effectiveness on many of the drinks residues decreased as the marks aged. Basic Violet 3 was shown to stain vegetable oil spread, used cooking oil, sun cream, anti-seize compound, Swarfega, used engine oil, and its effectiveness on olive oil, sunflower oil and mayonnaise increased as marks aged. 
Solvent Black 3 and Natural Yellow 3 both produced strong staining on butter, vegetable oil spread, lard, mayonnaise, hand cream, used cooking oil, lipstick, engine grease, with solvent black 3 also giving good results for red wine, orange juice, ketchup, cough syrup, WD40, Swarfega, sun cream, and moisturiser. Four of these contaminants (olive oil, butter, vegetable oil spread and hand cream) were subsequently used by Cadd et al. (2011) in comparative trials of the effectiveness of solvent black 3 formulations.

The study by Gaskell et al. also demonstrated that white powder and black powder suspension formulations were more effective than any single lipid reagent across the broad range of contaminants studied. These processes were effective because in most cases they targeted the latent fingermark constituents in preference to the contamination. It was also seen that in a real scenario where the nature of the contamination is unknown, there may be merit in sequential application of reagents that target different classes of 'greasy' contaminant.

\subsubsection{Condom lubricants}

Amongst other possible contaminants, condom lubricants are those relating to either consensual sexual activity or sexual assault. As such, their detection and mapping may provide circumstantial evidence which may become corroborative of the victim/defendant's statements or of other evidence such as the packet of condoms from which the lubricants have originated, found at the victim/defendant's premises. The crime and analytical scenarios are those according to which the individual wearing/using the condom would have contaminated their fingertips with the viscous matrix (lubricants) wetting the condom itself. Upon contact with a surface, a fingermark would be transferred containing the condom lubricants. MALDI MS has been used in both profiling and imaging mode to detect and visualise condom lubricants from a range of condoms (Bradshaw et al., 2011; Bradshaw et al., 2013a). Crucially, the visualisation of lubricants generates molecular images of the fingermark thus linking the biometric information with the circumstances of the event under investigation.

Lubricants are complex matrices made up many different substances including polymers. These compounds ionise particularly well in MALDI and many types of polydimethylsiloxane-based and polyethylenglycol-based polymers as well as the spermicidal nonoxynol-9 and co-polymers were detected within the seven condoms investigated by Bradshaw et al. (2013a). Mirabelli et al. (2013) used desorption electrospray ionization mass spectrometry (DESI) to detect compounds in condom lubricants in the lower $m / z$ range (50-1000 and 50-2000) and determined the presence of low molecular weight polymers (nonoxynol-9, polyethylene glycol, and polydimethylsiloxane) and small additive molecules including $\mathrm{N}$-methylmorpholine, $\mathrm{N}$-octylamine, $\mathrm{N}, \mathrm{N}$-dibutyl formamide, and isonox 132 in condoms. Molecular images of the condom contaminated marks were also generated.

Every condom and condom brand showed a unique "polymeric fingerprint" as condom lubricants are always made up of mixtures of different polymers and both 2013 studies showed it was possible to distinguish amongst them. However, it is important to create a reference database of condom lubricant polymer spectra for each analytical technique being used if this is to be validated for practical use.

It was observed (Bradshaw et al., 2013a) that fingermark images could still be obtained after 3 months from the deposition of the "condom contaminated" fingermark, demonstrating persistence 
of this particular contaminant. This is particularly important in rape cases where, for various reasons, the victim may not immediately report the crime to the police.

\subsubsection{Explosives, gunshot residue and metal ions}

Other contaminants of forensic significance that may be found in latent fingermarks include explosives residues, gunshot residues, and metal ions from the handling of metal articles such as weapons and an overview of different studies and the species that have been detected is given in Table 4.

These species have been little utilised in the visualisation of fingermarks, although their distribution on the hands can be mapped to provide potentially important operational context. It has been recognised that metal ions can transfer into the sweat on the hands when metal items are held, and the 3-(2-pyridyl)-5, 6-diphenyl-1,2,4-triazine (PDT) complexing agent has been proposed for the detection of iron ions transferred during the handling of firearms (Almog \& Glattstein, 1997). However, this method requires the impression to be developed in situ by the reagent being sprayed directly onto the hand. Bleay et al. (2014) have subsequently shown that metal ions present on the hand can be transferred from the hand onto other surfaces within the fingermark residues, and demonstrated the simultaneous detection and mapping of copper and lead ions in a finger/palm print taken from the hand using a gelatin lifter. Rubeanic acid was used as the development reagent in this case.

\section{UTILISATION OF FINGERMARK CHEMISTRY IN SEQUENTIAL TREATMENT}

It has been demonstrated that various individual constituents, or classes of them, can be targeted by a range of different chemical development processes. The fact that the use of a single chemical development reagent can leave a substantial proportion of the chemicals deposited in the fingermark still available for reaction means that it is possible to use a series of processes in sequence to maximise recovery rates.

Studies in the 1970s and 1980s resulted in processing sequences being proposed for several surfaces encountered operationally (Goode \& Morris, 1983; Kent, 1986). The sequences iodine - ninhydrin silver nitrate and ninhydrin - physical developer were established for use on porous surfaces, however the subsequent introduction of methods such as cyanoacrylate fuming and metal toning of ninhydrin necessitated further systematic study. This was first addressed by Lennard \& Margot (1988), who considered techniques established at the time in terms of whether they were thought to develop eccrine or sebaceous deposits. They proposed revised fingermark processing sequences that incorporated the use of fluorescent dye stains and lighting techniques, such as episcopic lighting, into appropriate points in the sequence.

In general, the processing sequences that have been proposed follow a logical order of processes. The first stage is to use non-contact, non-destructive processes (e.g. visual examination and fluorescence examination) which leave chemical constituents unaffected, followed by vapour phase processes or dry powders that have minimal impact. Finally, liquid-based chemical enhancement processes can be used, with organic solvent-based formulations typically being used before aqueous formulations because they are generally less destructive. By using this progressive approach it is 
possible to use sequences of chemical/physical processes and continue to develop additional marks at each stage (Bandey, 2014).

This can be shown schematically in the overview of fingermark constituents shown in Figure 5 and the example of how these different constituents can be utilised in sequential processing (in this case for porous surfaces) given in Figure 6.

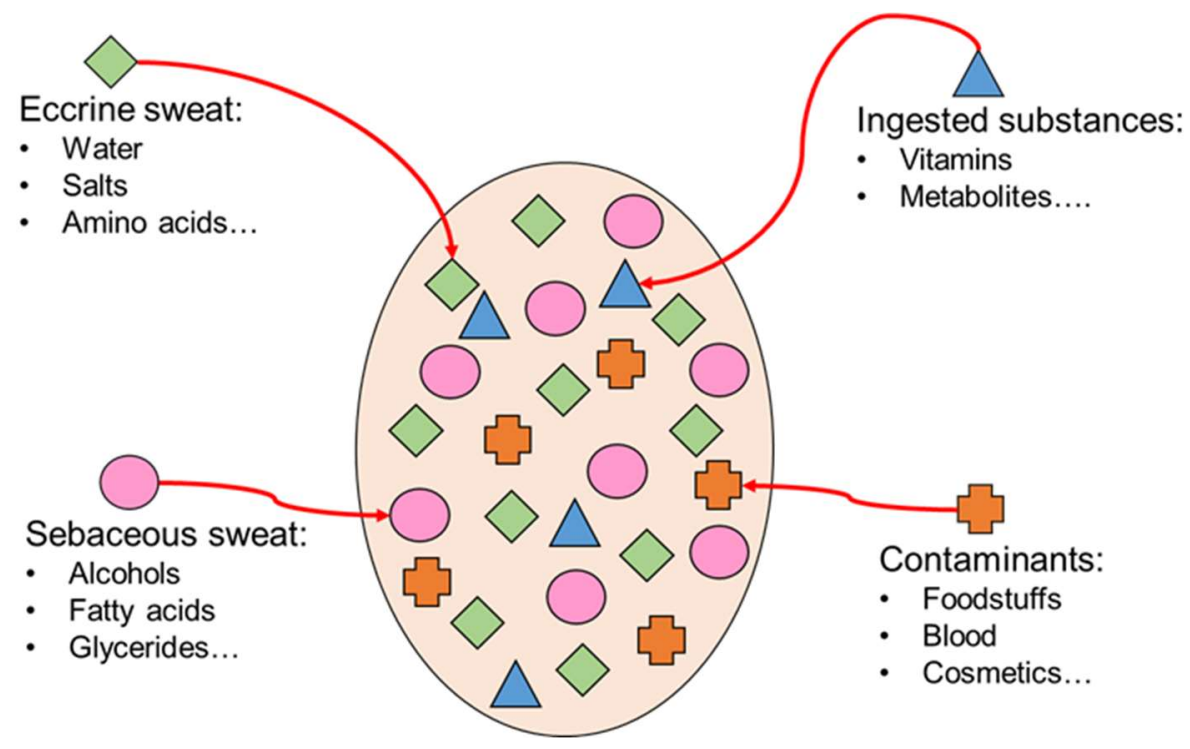

Figure 5. A schematic diagram of a fingermark showing the different constituents present.

\begin{tabular}{|l|l|}
\hline Fingermark schematic & Sequential processing stage \\
\hline & $\begin{array}{l}\text { Visual examination: Examination of the mark } \\
\text { using white light at different angles may reveal } \\
\text { marks. Some contaminants in the fingermark } \\
\text { (e.g. blood, mud) may absorb light, and the } \\
\text { fingermark may reflect or scatter light } \\
\text { differently to the surface providing contrast. }\end{array}$ \\
\hline
\end{tabular}




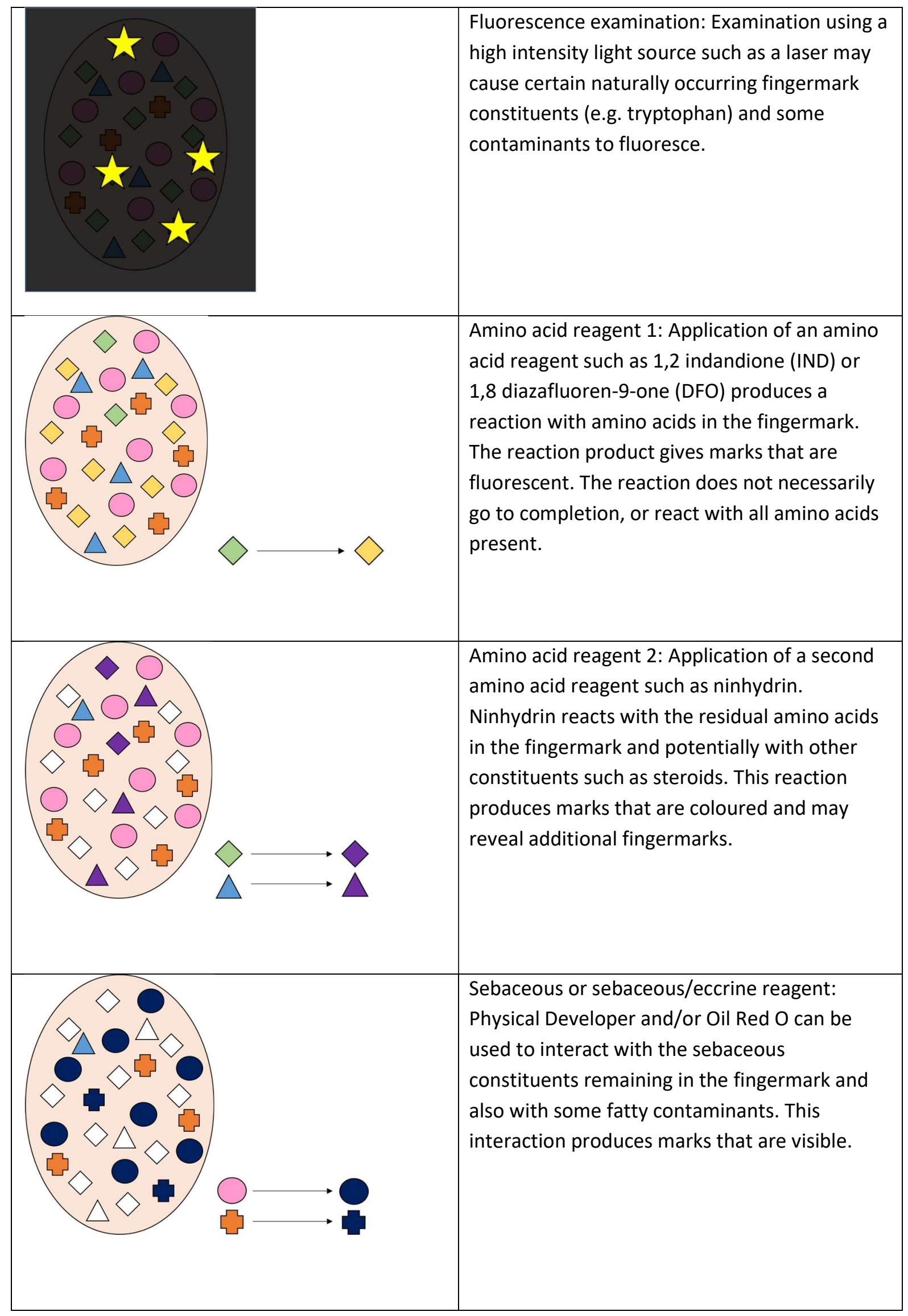




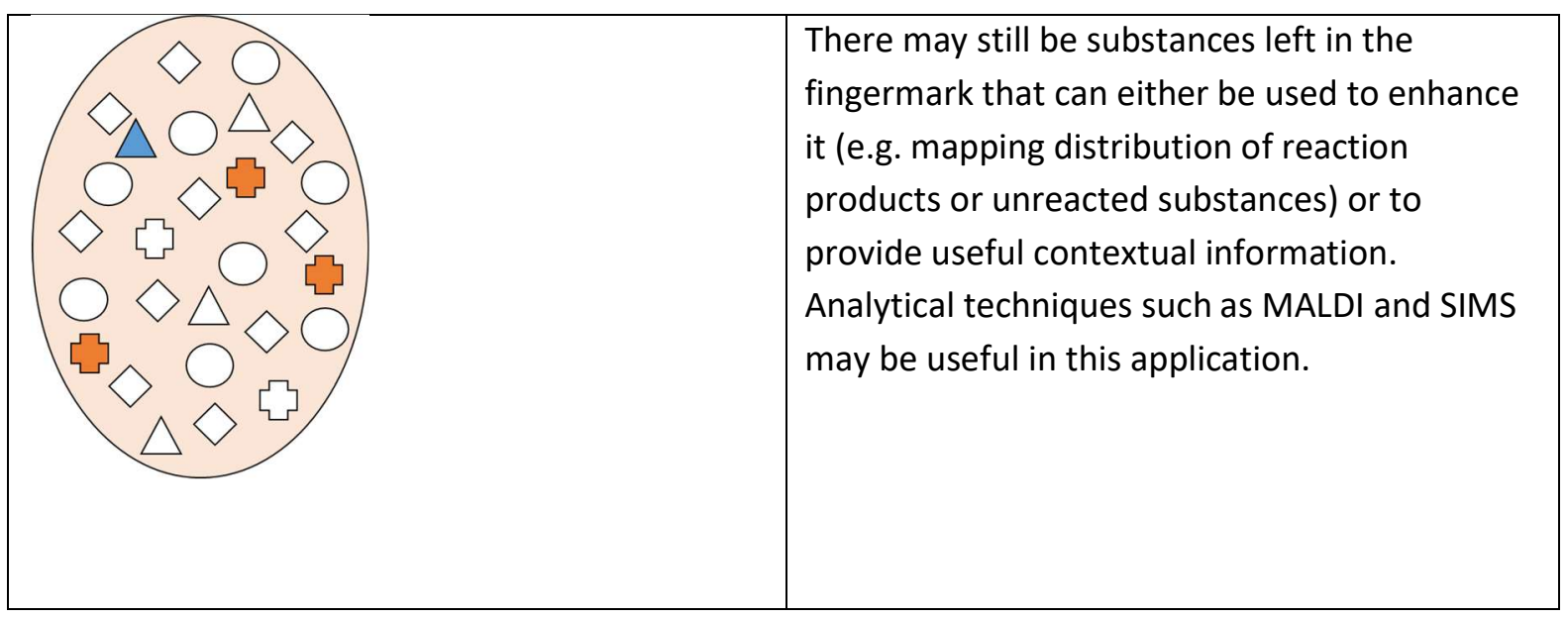

Figure 6. A schematic representation of a processing sequence on porous surfaces

Studies into processing sequences are less commonly reported than those that compare the effectiveness of single processes. Sequential studies on porous surfaces have been reported by Salama et al. (2007), McMullen et al. (2013), Marriott et al. (2014) and Bleay et al. (2019). All these studies confirm that the most effective sequence for developing fingermarks on porous surfaces is 1,- indandione (previously DFO) followed by ninhydrin, and finally physical developer. Oil Red O can be incorporated into these sequences, and indeed McMullen et al. have shown that it can be effective in developing additional marks when used in sequence after 1,2-indandione and ninhydrin. However, the choice of solvent used in the reagents can affect which processes remain effective. Salama et al. observed that when petroleum ether was used as the solvent for 1,2-indandione and ninhydrin, many of the constituents targeted by Oil Red O were dissolved and Oil Red O was ineffective when used subsequently. The 1,2-indandione and ninhydrin formulations used by McMullen et al. used alternative solvents (HFE 7100) which did not have the same detrimental impact. Marriott et al. looked at the incorporation of a lipid reagent, Nile Red, into processing sequences but observed that the increased benefit over the 1,2-indandione - ninhydrin - physical developer sequence was minimal. Bleay et al. looked at the potential benefit of using a blue toner to further enhance the silver marks produced by physical developer and found that this process could produce a significant increase in the number of marks visualised.

There are fewer studies into sequences for non-porous surfaces and those reported have focused on a subset of the wide range of substrates encountered. Downham et al. (2012) looked at sequences for polymer bags and packaging, and found that the process found most effective in equivalent studies in the mid-1980s (vacuum metal deposition) had become effective than both cyanoacrylate fuming with Basic Yellow 40 (BY40) staining and the powder suspensions process. This was attributed to an increase in the recycled polymer content of packaging material and guidance on processing such surfaces was changed accordingly (Bandey, 2014). Basic violet 3 continued to develop a small percentage of additional marks when used at the end of a sequence after all of these processes.

A comparison of different processing sequences was necessitated by the introduction of polymer banknotes in several countries. The first of these studies (Jones et al., 2003) was conducted on Australian banknotes and found a sequence of visual and fluorescence examination, cyanoacrylate 
fuming, vacuum metal deposition followed by fluorescent dye staining to be most effective. A similar study on Canadian polymer banknotes (Lam et al., 2014) came to a similar conclusion. A study on UK banknotes was conducted and reported by Downham et al. (2018). A sequence using black magnetic powder followed by powder suspensions was found to be the most effective sequence using established processes whilst a sequence including novel infrared fluorescent powders also showed promising results.

It is recognised that however effective these processing sequences may be, it is probable that a proportion of the marks present may still go undetected. An alternative approach for porous surfaces was explored by Jaber et al. (2012), who used 'reverse development' using gold and silver nanoparticles to selectively darken the paper background, revealing any fingermarks present visible as white outlines. Because the paper composition will be constant but the fingermark composition variable, it was hoped that selectively developing the paper background may reveal more of the fingermarks present.

As illustrated in Figure 6 and discussed in previous sections, mass spectrometry-based techniques with imaging capability may have a role in revealing additional ridge detail, even after full processing sequences involving conventional developers have been applied. Due to its nature, mass spectrometry is a multiplexed technique. This means that it can detect hundreds to thousands of compounds in one analysis in both a targeted and untargeted approach. In theory, if a conventional development technique targets a certain class of compounds and these compounds are no longer detectable because they have already reacted, mass spectrometry has to ability to target other classes of compounds. For example, cyanoacrylate fuming generates a white polycyanoacrylate deposit on fingermarks. It can be hypothesised that whilst higher molecular weight species such as peptides and proteins could be trapped within the intricate polymer network, lower molecular weight species such as lipids could be available for detection. This has been demonstrated by Groeneveld et al. (2015) who were able to detect and image drugs, metabolites and fatty acids in fingermarks after both cyanoacrylate fuming and vacuum metal deposition.

The range of mass spectrometry techniques available differ in terms of the compounds they are most suited to detect. For example, while SIMS can target, amongst other species, electrolytes, MALDI cannot. Conversely, while MALDI is capable of detecting high molecular weight peptides and proteins, SIMS cannot. It is necessary to take these differences into consideration if selecting mass spectrometry methods to 'fill in' ridge detail at the end of a processing sequence.

Both MALDI, and to a lesser extent, SIMS, have demonstrated that they can detect and image compounds that remain after full processing sequences, and/or can be used to reveal more information than conventional development processes.

MALDI MSI has been shown capable of revealing additional ridge detail in fingermarks previously processed using VMD, cyanoacrylate fuming and BY40 dye staining (Groeneveld et al., 2015), powders, ninhydrin, acid black 1 (Bradshaw et al. 2013b; Bradshaw et al., 2014, Patel et al.., 2016), acid yellow 7, leucocrystal violet (Kennedy et al., 2020) and indandione. Even when a specific compound or classes of compounds have been targeted by conventional techniques, these species do not become automatically unavailable for detection using MALDI. Bradshaw et al. (2014) have demonstrated that it is possible to detect and image intact haemoglobin in marks previously enhanced with acid black 1 whilst Patel, Cicatiello et al. (2015) have been able to detect a variety of 
blood specific proteins in a 9 year old acid black 1 enhanced palm print on a tile. The same capability is retained if ninhydrin is used. Francese (2019) showed that it was possible to detect haemoglobin in a mark on fabric developed 32 years previously using ninhydrin, via a MALDI based proteomic approach.

TOF-SIMS also has the potential to produce images of fingermarks in situations where conventional reagents do not. Bailey et al. (2013) demonstrated how TOF-SIMS could be used to enhance the quality of ridge detail in marks only partially developed by conventional reagents. The authors showed examples of enhanced visualisation of ridge detail by SIMS on marks previously developed on aluminium foil using cyanoacrylate fuming/BY40. SIMS also produced images of fingermarks on glass that had been buried in soil and marks deposited on the handle of a hand grenade, both of which could not be developed conventionally. Similarly, Thandauthapani et al. (2018) have shown that SIMS can be effective in detecting ridge detail on stainless steel knife blades where cyanoacrylate fuming has proved to be relatively ineffective. However, the latter examples discuss the use of SIMS as an alternative to conventional processes rather than used to enhance detail at the end of a sequence. Unpublished research indicates that SIMS does have potential to be used in this way, but further work is required to identify compatibility with other processes.

\section{UTILISATION OF FINGERMARK CHEMISTRY TO OBTAIN ADDITIONAL CONTEXTUAL INFORMATION}

Due to their specificity and sensitivity, mass spectrometry techniques are able to exploit the molecular make up of fingermarks to provide contextual information. A good example is illustrated by Bradshaw et al. (2017) in the application of MALDI MSI to operational police casework. A suspect accused of harassment had been apprehended and tested positive for cocaine abuse. MALDI MSI was performed on the powdered fingerprint recovered from the interior side of a PVC window frame on a tape lift. The analyses, performed 26 days after fingermark recovery, confirmed cocaine abuse but also detected a unique metabolite named cocaethylene, indicative of simultaneous consumption of cocaine and alcohol. It is important to note that during the police interview the suspect had denied alcohol consumption and had he not confessed just before the court hearing, the complete information on his state of mind would have not been obtained without employing MALDI MSI.

Hinners et al. (2018) have also employed MALDI MS Imaging to detect, visualise and source attribute active ingredients from bug sprays and sunscreens, as well as food oils, alcohols, and citrus fruits. The determination of the presence of these and other compounds that are picked up on the fingertips may reveal lifestyle information that could potentially inform investigations. In their work the authors suggest that while one compound may be insufficient to provide reliable contextual information, the simultaneous determination of multiple compounds from different sources (for example from consumer products, foods, and alcohols) may give important insights into a person's lifestyle.

Another example in which non-destructive methods can be used first followed by methods that exploit the molecular make-up of the fingermark still available to provide contextual information has been reported by Bradshaw et al. (2013a). Although the following may not routinely occur, a scenario in which "condom-contaminated" marks are searched and photographed first using 
specialised lights, followed by tape lift and analysis by ATR-FTIR and by a second lift subjected to MALDI MSI analysis to complement (if necessary) the biometric information and provide additional contextual evidence, is shown to be possible (Figure 7).

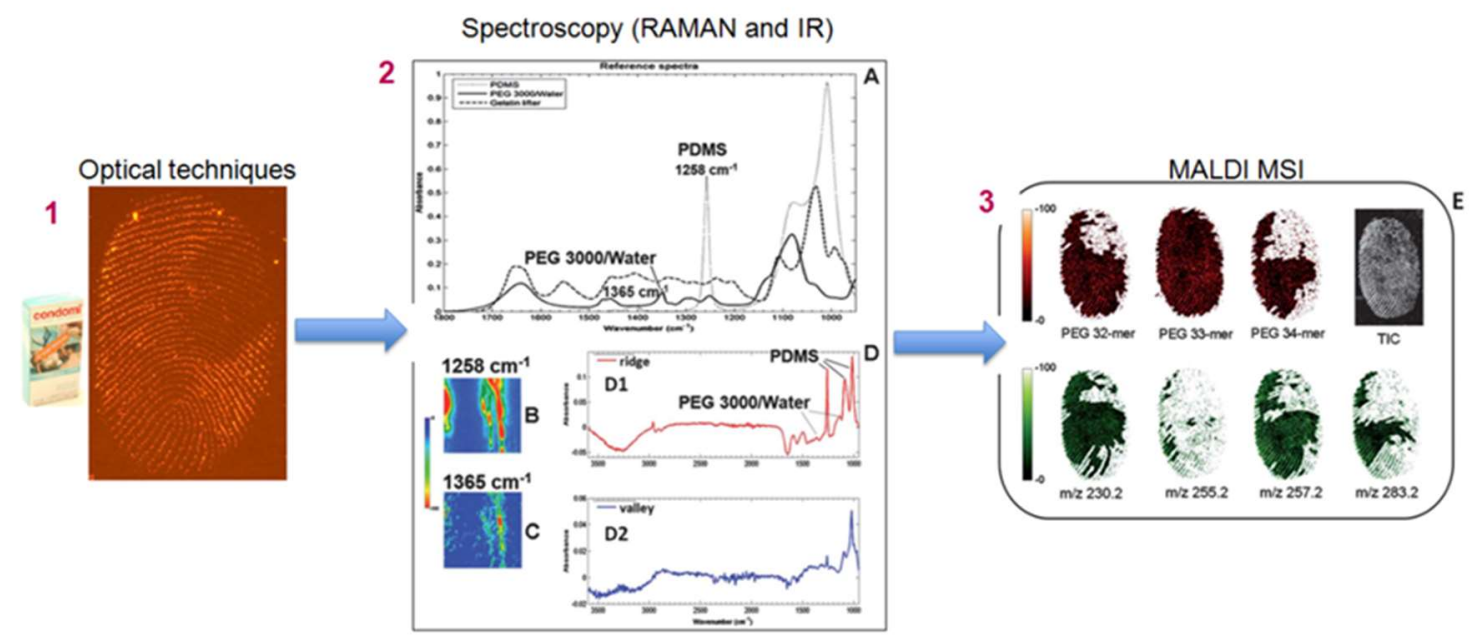

Figure 7. Combined specialised light- ATR-FTIR imaging-MALDI MSI analysis of a Condomi Max Love contaminated fingermark. (1). Fluoresence image of the mark using laser illumination at a wavelength of $532 \mathrm{~nm}$ and an orange viewing filter (cut-on $549 \mathrm{~nm}$ ). (2) A shows the reference FTIR spectra of vinyl PDMS (at $1258 \mathrm{~cm}^{-1}$ ) and PEG 3000 (at $1365 \mathrm{~cm}^{-1}$ ) superimposed with the spectrum of a BVDA gelatin lifter. Panels $B$ and $C$ show the ATR-FTIR image of PDMS at $1258 \mathrm{~cm}^{-1}$ and the ATRFTIR image of PEG at $1365 \mathrm{~cm}^{-1}$ present on the same ridges of a Condomi Max Love contaminated fingermark selected region. Panel D shows two ATR-FTIR spectra from the ridge (D1) and the valley (D2) (high and low concentration of the two polymers respectively). (3) MALDI MS images of 32-mer, 33-mer and 34-mer PEG ion signals, the complete ridge pattern provided by the image of the total ion current (TIC), as well as a small sample of the many fatty acids detected. Adapted from Bradshaw, Wolstenholme et al. (2013) with permission from The Royal Society of Chemistry.

Mass spectrometry-based techniques have also been investigated for their potential to add context to a forensic timeline. A question that is sometimes posed when fingermarks are developed on an incriminating document is whether the paper was handled before or after the incriminating content was present. This issue has been addressed by several researchers using SIMS (Bailey et al., 2010; Bright et al., 2012, Attard-Montalto et al., 2013; Attard-Montalto et al., 2014), with the general approach being to identify signals from chemical species unique to both the ink and fingermark components. It has been demonstrated that it is possible to discriminate between the 'ink over fingerprint' and 'fingerprint over ink' scenarios using both imaging and depth profiling modes prior to development of the fingermark. However, use of a chemical reagent to develop the fingermarks can lead to redistribution of constituents and makes discrimination more difficult. The most comprehensive study of this type (Attard-Montalto et al., 2014) found that the ability to discriminate the order of fingermark and ink was influenced by printing method and fingermark development technique used. Discrimination was best on laser printed documents with fingermarks developed using iodine fuming or 1,2 indandione. 
It should also be noted that chemical differences between fingermarks from different donors have also been used to separate and image overlapping fingermarks (Bradshaw et al., 2012). In this case the technique used was MALDI MSI.

\section{Conclusion}

The chemistry of the residue that is deposited in fingermarks is highly complex, and compositional analysis has detected hundreds of different substances that may be present. This is despite the fact that the amount of material that may be deposited is minimal, of the order of micrograms. The chemical composition has traditionally been exploited in a forensic context by a range of different reagents that target different constituents of the fingermark. The suite of processes that have been proposed for fingermark enhancement are highly effective, with high sensitivities for the most abundant constituents and the capability to be used sequentially to maximise the number of fingermarks recovered. Although not all constituents present are currently exploited for visualisation, there is probably minimal, if any benefit in seeking developers specific to any constituents not already specifically targeted if increases in overall effectiveness are required.

The future directions for the exploitation of fingermark chemistry are the synthesis of developers with increased specificity to a constituent or contaminant of particular interest (e.g. tagged nanoparticles that bind to specific metabolites or body fluids), and the use of analytical techniques to characterise and spatially map the substances present. The potential of MS-based techniques to contribute to improved biometric information as well as to contextual information is vast.

From a solely identification perspective, MS imaging techniques are crucially capable of "filling in the ridge detail gaps" after the application of conventional processes and there is therefore a potential role for such techniques as a final sequential process in a serious crime investigation. However, the main area of anticipated growth is their potential to provide additional contextual information (e.g. about substances handled, lifestyle, potential pathologies from the detection of medications etc.) simultaneously with the provision of the biometric information (imaging) or beyond identification (profiling). Such intelligence can be used to inform and steer the investigations faster and potentially with savings to the public purse. For this reason the research must have a dynamic focus to keep up with the ever increasing number of possible contaminants (such as newly synthesised drugs, medications or changing molecular composition in day care products or others); this would also require that the protocols that are available will need to be constantly tested against new substances. Capabilities are always accompanied by limitations and drawbacks and each MS Imaging technique will have their own.

It is also important to mention that different MS instrumentation, employing the same MS technique, may perform vastly differently within the protocols available. The authors believe that this issue will need to be addressed as part of the validation of these techniques, the requirements for which may change depending on the particular criminal justice system environment and judicial systems. The validation process should also encompass the elucidation of the impact and the extent to which MS techniques affect subsequent processes for extraction of additional biometric or biological information. Whilst some studies have been published and others are in progress, much of this knowledge is presently missing and is required to allow appropriate positioning of these 
processes in the forensic workflow of fingermark visualisation, identification, and for use as a source of further biological information.

Another challenge for operational implementation of such methods is the need to create comprehensive reference databases for the contaminants of operational interest. One such example relates to the creation of a condom lubricant mass spectral libraries discussed earlier in the "Contaminants" section. The generation of libraries of this kind is often regarded as a "repetitive exercise" and does not attract funding from research bodies.

Finally, there is a need for the technology that enables detection and analysis of this complex chemistry to be made as accessible as possible, whether by miniaturisation to make equipment portable, developing simple interfaces to make operation straightforward, or automation of complex analyses. The closer such techniques can be brought to the 'operational' environment, the more widely they can be utilised. The points above describe significant barriers to these techniques realising their full operational potential and all require collaborative and international approaches if they are to be overcome.

Funding Information

The authors would like to acknowledge the EPSRC grant EP/R031118/1

\section{References}

Abedlhamid, M., Fortes, F.J., Harith, M.A., \& Laserna, J.J. (2011). Analysis of explosive residues in human fingerprints using optical catapulting-laser-induced breakdown spectroscopy. Journal of Analytical Atomic Spectrometry, 26, 1445-1450. https://doi.org/10.1039/c0ja00188k

Allman, D., \& Pounds, C. A., (1992). The Specificity of Diaminobenzidine for the Detection of Blood (Technical Note, April 1992). Central Research and Support Establishment, The Forensic Science Service.

Almog, J., Sasson, Y., \& Anati, A. (1979). Chemical Reagents for the Development of Latent Fingerprints II: Controlled Addition of Water Vapor to lodine Fumes - A Solution to the Ageing Problem. Journal of Forensic Sciences, 24(2), 431-6. https://doi.org/10.1520/JFS10850J

Almog, J., Hirshfield, A., Frank, A., Grant, H., Harel, Z., \& Ittah, Y. (1992) 5-Methylthio Ninhydrin and Related Compounds: A Novel Class of Fluorogenic Fingerprint Reagents. Journal of Forensic Sciences, 37(3), 688-694. https://doi.org/10.1520/JFS11982J

Almog, J., \& Glattstein, B. (1997). Detection of Firearms Imprints on Hands of Suspects: Study of the PDT-Based Field Test. Journal of Forensic Sciences, 42(6), 993-996.

https://doi.org/10.1520/JFS14250J

Almog, J., Sears, V. G., Springer, E., Hewlett, D. F., Walker, S., Weisener, S., Lidor, R., \& Bahar, E. (2000). Reagents for the Chemical Development of Latent Fingerprints: Scope and Limitations of 
Benzo[f]ninhydrin in Comparison to Ninhydrin. Journal of Forensic Sciences, 45(3), 538-544. https://doi.org/10.1520/JFS14726J

Almog, J., Cohen, Y., Azoury, M., \& Hahn, T-R. (2004). Genipin - A Novel Fingerprint Reagent with Colorimetric and Fluorogenic Activity. Journal of Forensic Sciences, 49(2), 255-7. https://doi.org/10.1520/JFS2003321

Almog, J., Klein, A., Davidi, I., Cohen, Y., Azoury, M., \& Levin-Elad M. (2008). Dual Fingerprint Reagents with Enhanced Sensitivity: 5-Methoxy- and 5-Methylthioninhydrin. Journal of Forensic Sciences, 53(2), 364-367. https://doi.org/10.1111/j.1556-4029.2008.00671.x

Archer, N. E., Charles, Y., Elliott, J. A., \& Jickells, S. (2005). Changes in the lipid composition of latent fingerprint residue with time after deposition on a surface. Forensic Science International, 54(2-3), 224-239. https://doi.org/10.1016/i.forsciint.2004.09.120

Attard-Montalto, N., Ojeda, J. J., \& Jones, B. J. (2013). Determining the order of deposition of natural latent fingerprints and laser printed ink using chemical mapping with secondary ion mass spectrometry. Science \& Justice, 53(2), 2-7. https://doi.org/10.1016/j.scijus.2012.05.007

Attard-Montalto, N., Ojeda, J. J., Reynolds, A., Ismail, M., Bailey, M., Doodkorte, L., de Puit, M. \& Jones, B. J. (2014). Determining the chronology of deposition of natural fingermarks and inks on paper using secondary ion mass spectrometry. Analyst, 139, 4641-4653.

https://doi.org/10.1039/C4AN00811A

Atherton, T., Croxton, R., Baron, M., Gonzalez-Rodriguez, J., Gámiz-Gracia, L. \& García-Campaña, A.M. (2012). Analysis of amino acids in latent fingerprint residue by capillary electrophoresis-mass spectrometry. Journal of Separation Science, 35 (21), 2994-2999.

https://doi.org/10.1002/jssc.201200398

Atherton, T. (2013). Analysis of the composition of aged fingerprints and their correlation to the powder suspension technique [Unpublished PhD thesis]. University of Lincoln.

Bailey, M J., Jones, B. N., Hinder, S., Watts, J., Bleay, S., \& Webb, R.P. (2010). Depth profiling of fingerprint and ink signals by SIMS and MeV SIMS. Nuclear Instruments and Methods in Physics Research Section B: Beam Interactions with Materials and Atoms, 268, 1929-1932.

https://doi.org/10.1016/j.nimb.2010.02.104

Bailey, M. J., Bright, N. J., Croxton, R. S., Francese, S., Ferguson, L. S., Hinder, S., Jickells, S., Jones, B. J., Jones, B. N., Kazarian, S. G., Ojeda, J. J., Webb, R. P., Wolstenholme, R., \& Bleay, S. (2012). Chemical characterization of latent fingerprints by matrix-assisted laser desorption ionization, timeof-flight secondary ion mass spectrometry, mega electron volt secondary mass spectrometry, gas chromatography/mass spectrometry, X-ray photoelectron spectroscopy, and attenuated total reflection Fourier transform infrared spectroscopic imaging: an intercomparison. Analytical Chemistry, 84(20), 8514-23. https://doi.org/10.1021/ac302441y 
Bailey, M. J., Ismail, M., Bleay, S., Bright, N., Levin Elad, M., Cohen, Y., Geller, B., Everson, D., Costa, C., Webb, R. P., Watts, J. F., \& de Puit, M. (2013). Enhanced imaging of developed fingerprints using mass spectrometry imaging. Analyst,138, 6246-6250. https://doi.org/10.1039/C3AN01204B

Bailey, M.J., Bradshaw, R., Francese, S., Salter, T. L., Costa, C., Ismail, M. P., Webb, R., Bosman, I., Wolff, K., \& de Puit, M. (2015). Rapid detection of cocaine, benzoylecgonine and methylecgonine in fingerprints using surface mass spectrometry. Analyst, 140(18), 6254-9.

https://doi.org/10.1039/C5AN00112A

Bailey, M., Randall, E. C., Costa, C., Salter, T. L., Race, A. M., de Puit, M., Koeberg, M., Baumert, M., \& Bunch, J. (2016). Analysis of Urine, Oral fluid and Fingerprints by Liquid Extraction Surface Analysis Coupled to High Resolution MS and MS/MS - Opportunities for Forensic and Biomedical Science. Analytical Methods, 16, 3373-3382. https://doi.org/10.1039/C6AY00782A

Banas, A., Banas, K., Breese, M. B. H., Loke, J., Heng Teo, B., \& Lim, S. K. (2012). Detection of microscopic particles present as contaminants in latent fingerprints by means of synchrotron radiation-based Fourier transform infra-red micro-imaging. Analyst, 137, 3459-3465.

https://doi.org/10.1039/C2AN35355E

Banas, A., Banas, K., Breese, M. B. H., Loke, J., \& Lim, S. K. (2014). Spectroscopic detection of exogenous materials in latent fingerprints treated with powders and lifted off with adhesive tapes. Analytical and Bioanalytical Chemistry, 406, 4173-4181. https://doi.org/10.1007/s00216-014-7806-8

Baniuk, K. (1990). Determination of age of fingerprints. Forensic Science International, 46(1-2), $133-$ 137 https://doi.org/10.1016/0379-0738(90)90151-N

Barnes, J. G. (2011). Chapter 1: History. in The Fingerprint Sourcebook, NIJ, July 2011, https://nij.ojp.gov/library/publications/fingerprint-sourcebook (accessed 08/05/2020)

Benton, M., Rowell. F., Sundar, L. \& Jan, M. (2010a). Direct detection of nicotine and cotinine in dusted latent fingermarks of smokers by using hydrophobic silica particles and MS. Surface Interface Analysis, 42, 378-385. https://doi.org/10.1002/sia.3112

Benton, M., Chua, M.J., Gu, F., Rowell, F., Ma, J.(2010b) Environmental nicotine contamination in latent fingermarks from smoker contacts and passive smoking. Forensic Science International, 200, 28-34. https://doi.org/10.1016/j.forsciint.2010.03.022

Bleay, S. M., Grove, L. E., Kelly, P. F., King, R. S. P., Mayse, K., Shah, B. C., \& Wilson, R. (2014) Noninvasive detection and chemical mapping of trace metal residues on the skin. RSC Advances, 4, 19525-19528. https://doi.org/10.1039/C4RA02463J

Bleay, S. M., Croxton, R. S. \& de Puit, M. (2018). Fingerprint Development Techniques: Theory and Application. Wiley. DOI:10.1002/9781119187400

Bleay, S., Fitzgerald, L., Sears, V. \& Kent, T. (2019). Visualising the past - An evaluation of processes and sequences for fingermark recovery from old documents. Science and Justice, 59(2), 125-137. https://doi.org/10.1016/i.scijus.2018.10.005 
Boddis, A.M. \& Russell, D.A. (2011). Simultaneous development and detection of drug metabolites in latent fingermarks using antibody-magnetic particle conjugates. Analytical Methods, 3, 519-523. https://doi.org/10.1039/C1AY05009E

Boddis, A.M., \& Russell, D. A. (2012). Development of aged fingermarks using antibody-magnetic particle conjugates. Analytical Methods, 4(3), 637-641. https://doi.org/10.1039/C2AY05692E

Bodziak, W. J., (1996). Use of Leuco-Crystal Violet to Enhance Shoeprints in Blood. Forensic Science International, 82, 45-52. https://doi.org/10.1016/0379-0738(96)01965-2

Bond, J. W. (2008) Visualisation of latent fingerprint corrosion of metallic surfaces. Journal of Forensic Sciences, 53(4), 812-822. https://doi.org/10.1111/i.1556-4029.2008.00738.x

Boniforti, L., Passi, S., Caprilli, F., \& Nazzaro-Porro, M. (1973). Skin surface lipids. Identification and determination by thin-layer chromatography and gas-liquid chromatography. Clinica Chimica Acta, 47(3), 223-231. https://doi.org/10.1016/0009-8981(73)90319-7

Boseley, R.E., Dorakumbura, B.N., Howard, H.L., de Jonge, M.D., Tobin, M.J., Vongsvivut, J., Ho, T.T.M., van Bronswijk, W., Hacket, M.J. \& Lewis, S.W. (2019) Revealing the elemental distribution wihtin latent fingermarks using synchrotron sourced X-ray fluorescence microscopy. Analytical Chemistry, 91, 10622-106. https://doi.org/10.1021/acs.analchem.9b01843

Bossers, L. C. A. M., Roux, C., Bell, M., \& McDonagh, A. M. (2011). Methods for the enhancement of fingermarks in blood. Forensic Science International, 210(1-3), 1-11.

https://doi.org/10.1016/i.forsciint.2011.04.006

Bradshaw, R., Wolstenholme, R., Blackledge, R. D., Clench, M. R., Ferguson, L. S., \& Francese, S. (2011). A novel matrix-assisted laser desorption/ionisation mass spectrometry imaging based methodology for the identification of sexual assault suspects. Rapid Communications in Mass Spectrometry, 25(3), 415-22. https://doi.org/10.1002/rcm.4858

Bradshaw, R., Rao, W., Wolstenholme, R., Clench, M. R., Bleay, S., \& Francese, S. (2012). Separation of overlapping fingermarks by matrix assisted laser desorption ionisation mass spectrometry imaging. Forensic Science International, 222(1-3), 318-26.

https://doi.org/10.1016/i.forsciint.2012.07.009

Bradshaw, R., Wolstenholme, R., Ferguson, L. S., Sammon, C., Mader, K., Claude, E., Blackledge, R. D., Clench, M. R., \& Francese, S. (2013a). Spectroscopic imaging based approach for condom identification in condom contaminated fingermarks. Analyst, 138(9), 2546-57.

https://doi.org/10.1039/C3AN00195D

Bradshaw, R. Bleay, S., Wolstenholme, R., M. R., Clench, \& Francese, S. (2013b). Towards the integration of matrix assisted laser desorption ionisation mass spectrometry imaging into the current fingermark examination workflow. Forensic Science International, 232(1-3), 111-124.

https://doi.org/10.1016/i.forsciint.2013.07.013 
Bradshaw, R., Bleay, S., Clench, M. R., \& Francese, S. (2014a). Direct detection of blood in fingermarks by MALDI MS profiling and imaging. Science \& Justice, 54(2), 110-7.

https://doi.org/10.1016/i.scijus.2013.12.004

Bradshaw, R. \& Francese, S. (2014b). Matrix-assisted laser desorption ionisation tandem mass spectrometry imaging of small molecules from latent fingermarks. Spectroscopy Europe, 26(4), 6-8.

Bradshaw, R., Denison, N., \& Francese, S. (2017). Implementation of MALDI MS profiling and imaging methods for the analysis of real crime scene fingermarks. Analyst, 142(9), 1581-1590.

https://doi.org/10.1039/C7AN00218A

Brennan, J., Bramble, S., Crabtree, S. \& Wright, G. (1995). Fuming of latent fingerprints using dimethylaminocinnamaldehyde. Journal of Forensic Identification, 45(4), 373-380.

Bright, N. J., Webb, R. P., Bleay, S., Hinder, S., Ward, N. I., Watts, J. F., Kirby, K. J., \& Bailey, M. J. (2012). Determination of the deposition order of overlapping latent fingerprints and inks using secondary ion mass spectrometry. Analytical Chemistry, 84(9), 4083-4087.

https://doi.org/10.1021/ac300185j

Bright, N. J., Willson, T. R., Driscoll, D. J., Reddy, S. M., Webb, R. P., Bleay, S., Ward, N. I., Kirkby, K. J., \& Bailey, M. J. (2013). Chemical changes exhibited by latent fingerprints after exposure to vacuum conditions. Forensic Science International, 230(1-3), 81-86.

https://doi.org/10.1016/i.forsciint.2013.03.047

Cadd, S., Islam, M., Manson, P., \& Bleay, S. (2015). Fingerprint composition and aging: A literature review. Science \& Justice, 55(4), 219-238. https://doi.org/10.1016/j.scijus.2015.02.004

Cadd, S., Li, B., Beveridge, P., O'Hare, W. T., Campbell, A., \& Islam, M. A comparison of visible wavelength reflectance hyperspectral imaging and Acid Black 1 for the detection and identification of blood stained fingerprints. Science \& Justice, 56(4), 247-255.

https://doi.org/10.1016/j.scijus.2015.12.007

Chadwick, S., Neskoski, M., Spindler, X., Lennard, C. \& Roux, C. (2017). Effect of hand sanitizer on the performance of fingermark detection techniques. Forensic Science International, 273, 153-160.

https://doi.org/10.1016/j.forsciint.2017.02.018

Cheeseman, R., \& DiMeo, L. A. (1995). Fluorescein as a Field-worthy Latent Bloodstain Detection System. Journal of Forensic Identification, 45(6), 631-646.

Chen, T., Schultz, Z.D., \& Levin, I.W. (2009). Infrared spectroscopic imaging of latent fingerprints and associated forensic evidence. Analyst, 134, 1902-1904. https://doi.org/10.1039/B908228J

Cheng, C., Kirkbride, T., Batchelder, D., Lacey, R., \& Sheldon, T. (1995). In Situ Detection and Identification of Trace Explosives by Raman Microscopy. Journal of Forensic Sciences, 40(1), 31-37. https://doi.org/10.1520/JFS13756J 
Costa, C., Webb, R., Palitsin, V., Ismail, M., de Puit, M., Atkinson, S., \& Melanie J Bailey, M. J. (2017). Rapid, Secure Drug Testing Using Fingerprint Development and Paper Spray Mass Spectrometry. Clinical Chemistry, 63(11), 1745-1752. https://doi.org/10.1373/clinchem.2017.275578

Costa, C., Ismail, M., Stevenson, D., Gibson, B., Webb, R., \& Bailey, M. (2019a). Distinguishing between contact and administration of heroin from a single fingerprint using high resolution mass spectrometry. Journal of Analytical Toxicology, 44(3), 218-225. https://doi.org/10.1093/jat/bkz088

Costa, C., Frampas, C., Longman, K. A., Palitsin, V., Ismail, M., Sears, P., Nilforooshan, R., \& Bailey, M. J. (2019b). Paper spray screening and LC-MS confirmation for medication adherence testing: a twostep process. Rapid Communications in Mass Spectrometry, https://doi.org/10.1002/rcm.8553

Clemons, K., Wiley, R., Waverka, K., Fox, J., Dziekonski, E., \& Guido F. Verbeck, G. F. (2013). Direct Analyte-Probed Nanoextraction Coupled to Nanospray lonization-Mass Spectrometry of Drug Residues from Latent Fingerprints. Journal of Forensic Sciences, 58(4), 875-880. https://doi.org/10.1111/1556-4029.12141

Cox, M. (1991). A study of the sensitivity and specificity of four presumptive tests for blood. Journal of Forensic Sciences, 36, 1503-1511. https://doi.org/10.1520/JFS13170J.

Croxton, R.S. (2008) Analysis of latent fingerprint components by gas chromatography-mass spectrometry [Unpublished PhD thesis]. University of Lincoln.

Croxton, R.S., Baron, M.G., Butler, D., Kent, T. \& Sears, V.G. (2010). Variation in amino acid and lipid composition of latent fingerprints. Forensic Science International, 199, 93-102. https://doi.org/10.1016/i.forsciint.2010.03.019

Cuthbertson, F. (1969). The Chemistry of Fingerprints (Report No. O 13/69). Atomic Weapons Research Establishment (AWRE).

Cuthbertson, F., \& Morris, J.R. (1972). The chemistry of fingerprints (SSCD Memorandum 332). Atomic Weapons Research Establishment (AWRE).

Czerwinska, J., Jang, M., Costa, C., Parkin, M. C., George, C., Kicman, A. T., Bailey, M. J., Dargan, P. I., \& Abbate, V. (2020). Detection of mephedrone and its metabolites in fingerprints from a controlled human administration study by liquid chromatography-tandem mass spectrometry and paper spraymass spectrometry. Analyst, 145, 3038-3048. https://doi.org/10.1039/C9AN02477H

Darke, D.J. \& Wilson, J.D. (1977). The analysis of free fatty acid component of fingerprints (Report G984). Atomic Energy Research Establishment (AERE).

Day, J. S., Edwards, H. G. M., Dobrowski, S. A., \& Voice, A M. (2004a). The detection of drugs of abuse in fingerprints using Raman spectroscopy I: latent fingerprints. Spectrochimica Acta Part A: Molecular and Biomolecular Spectroscopy, 60(3), 563-568. https://doi.org/10.1016/S1386$\underline{1425(03) 00263-4}$

Day, J. S., Edwards, H. G. M., Dobrowski, S. A., \& Voice, A M. (2004b). The detection of drugs of abuse in fingerprints using Raman spectroscopy II: cyanoacrylate-fumed fingerprints. Spectrochimica 
Acta Part A: Molecular and Biomolecular Spectroscopy, 60(8-9), 1725-1730.

https://doi.org/10.1016/j.saa.2003.09.013

De Alcaraz-Fossoul, J., Barrot-Feixat, C., Zapico, S. C., Mancenido, M., Broatch, J., Roberts, K. A., Carreras-Mari, C., \& Tasker, J. (2018). Ridge Width Correlations between Inked Prints and Powdered Latent Fingerprints. Journal of Forensic Sciences, 63(4),1085-1091. https://doi.org/10.1111/1556$\underline{4029.13656}$

Deininger, L., Patel, E., Clench, M. R., Sears, V., Sammon, C., \& Francese, S. (2016). Proteomics goes forensic: Detection and mapping of blood signatures in fingermarks. Proteomics, 16(11-12), 1707-17. https://doi.org/10.1002/pmic.201500544

De la Hunty, M., Moret, S., Chadwick, S., Lennard, C., Spindler, X., \& Roux, C. (2015). Understanding physical developer (PD): Part I--Is PD targeting lipids?. Forensic Science International, 257, 481-487. https://doi.org/10.1016/j.forsciint.2015.06.034

De la Hunty, M., Moret, S., Chadwick, S., Lennard, C., Spindler, X., \& Roux, C. (2015). Understanding Physical Developer (PD): Part II--Is PD targeting eccrine constituents?. Forensic Science International, 257, 488-495. https://doi.org/10.1016/j.forsciint.2015.08.029

de Puit, M., Ismail, M. \& Xu, X. (2014). LCMS analysis of fingerprints, the amino acid profile of 20 donors. Journal of Forensic Sciences, 59(2), 364-370. https://doi.org/10.1111/1556-4029.12327

Dennis, K. J., \& Shibamoto, T. (1989). Production of malonaldehyde from squalene, a major skin surface lipid, during UV-irradiation. Photochemistry \& Photobiology, 49(5), 711-6.

https://doi.org/10.1111/j.1751-1097.1989.tb08445.x

Dent, C. E. (1948). A Study of the Behaviour of some Sixty Amino-acids and other Ninhydrin-reacting Substances on Phenol-'collidine' Filter-paper Chromatagrams, with Notes as to the Occurrence of some of them in Biological Fluids. Biochemistry Journal, 43, 169-180.

De Paoli, G., Lewis, S. A. Sr., Schuette, E. L., Lewis, L. A., Connatser, R. M., \& Farkas, T. (2010). Photoand thermal-degradation studies of select eccrine fingerprint constituents. Journal of Forensic Sciences, 55(4), 962-9. https://doi.org/10.1111/j.1556-4029.2010.01420.x

Dorakumbura, B. N., Becker, T., \& Lewis, S. W. (2016). Nanomechanical mapping of latent fingermarks: A preliminary investigation into the changes in surface interactions and topography over time. Forensic Science International, 267, 16-24. https://doi.org/10.1016/i.forsciint.2016.07.024

Dorakumbura, B.N., Busetti, F., \& Lewis, S.W. (2019). Investigations into sampling approaches for chemical analysis of latent fingermark residue. Forensic Chemistry, 14, 100166.

https://doi.org/10.1016/i.forc.2019.100166

Dorakumbura, B. N., Busetti, F., \& Lewis, S. W. (2020). Analysis of squalene and its transformation by-products in latent fingermarks by ultrahigh-performance liquid chromatography-high resolution accurate mass Orbitrap ${ }^{\mathrm{TM}}$ mass spectrometry. Forensic Chemistry, 17, 100193.

https://doi.org/10.1016/i.forc.2019.100193 
Downham, R. P., Mehmet, S., \& Sears, V. G. (2012). A Pseudo-Operational Investigation into the Development of Latent Fingerprints on Flexible Plastic Packaging Films. Journal of Forensic Identification, 62(6), 661-682.

Downham, R. P., Ciuksza, T. M., Desai, H. J., \& Sears, V. G. (2017). Black Iron (II/III) Oxide Powder Suspension (2009 CAST Formulation) for Fingermark Visualization, Part 2: Surfactant Solution Component Investigations. Journal of Forensic Identification, 67(1), 145-167.

Downham, R. P., Brewer, E. R., King, R. S.P., \& Sears, V. G. (2018). Sequential processing strategies for fingermark visualisation on uncirculated $£ 10$ (Bank of England) polymer banknotes. Forensic Science International, 288, 140-158. https://doi.org/10.1016/j.forsciint.2018.04.018

Downing, D. T., \& Strauss, J. S. (1974). Synthesis and composition of surface lipids of human skin. Journal of Investigative Dermatology, 62, 228-244. https://doi.org/10.1111/1523-1747.ep12676793

Downing D.T., Strauss, J.S., Norton, L.A., Pochi, P.E., \& Stewart, M.E. (1977). The time course of lipid formation in human sebaceous glands. Journal of Investigative Dermatology, 69, 407-412. https://doi.org/10.1111/1523-1747.ep12510327

Drapel, V., Becue, A., Champod, C., \& Margot, P. (2009). Identification of promising antigenic components in latent fingermark residues. Forensic Science International, 184(1-3), 47-53. https://doi.org/10.1016/j.forsciint.2008.11.017

Dutt, M. C., Poh, T. T., (1980). Use of ninhydrin as a spray reagent for the detection of some basic drugs on thin layer chromatograms. Journal of Chromatography, 195, 133-138.

https://doi.org/10.1016/S0021-9673(00)81551-4

Emmons, E. D., Tripathi, A., Guicheteau, J. A., Christesen, S. D., \& Fountain, A. W. III. (2009). Raman Chemical Imaging of Explosive-Contaminated Fingerprints. Applied Spectroscopy, 63(11), 1197-1203. https://doi.org/10.1366/000370209789806812

Emmerson, B., Gidden, J., Lay, Jr., J.O., \& Durham, B. (2011). Laser desorption/ionization time-offlight mass spectrometry of triacylglycerols and other components in fingermark samples. Journal of Forensic Sciences, 56(2), 381-389. https://doi.org/10.1111/i.1556-4029.2010.01655.x

Faulds, H. (1880). On the Skin-Furrows of the Hand. Nature, 22, 605.

Ferguson, L. S., Wulfert, F., Wolstenholme, R., Fonville, J. M., Clench, M. R., Carolan, V.A., \& Francese, S. (2012). Direct detection of peptides and small proteins in fingermarks and determination of sex by MALDI mass spectrometry profiling. Analyst, 137(20), 4686-92. https://doi.org/10.1039/C2AN36074H

Ferguson, L. S., Creasey, S., Wolstenholme, R., Clench, M. R., \& Francese, S. (2013). Efficiency of the dry-wet method for the MALDI-MSI analysis of latent fingermarks. Journal of Mass Spectrometry, 48(6), 677-84. https://doi.org/10.1002/ims.3216 
Fernandez de la Ossa, M.A., Garcia-Ruiz, C. \& Amigo, J.M. (2014). Near infrared spectral imaging for the analysis of dynamite residues on human handprints. Talanta, 130, 315-321.

https://doi.org/10.1016/j.talanta.2014.07.026

Figueroa, B., Chen, Y., Berry, K., Francis, A. \& Fu, D. (2017). Label-free chemical imaging of latent fingerprints with stimulated Raman scattering microscopy. Analytical Chemistry, 89, 4468-4473. https://doi.org/10.1021/acs.analchem.6b04213

Flad, T., Bogumil, R., Tolson, J., Schittek, B., Garbe, C., Deeg, M., Mueller, C.A., \& Kalbacher, H. (2002). Detection of dermicidin-derived peptides in sweat by ProteinChip technology. Journal of Immunological Methods, 270, 53-62. https://doi.org/10.1016/s0022-1759(02)00229-6

Fowble, K. L., Musah, R. A. (2019) Simultaneous imaging of latent fingermarks and detection of analytes of forensic relevance by laser ablation direct analysis in real time imaging-mass spectrometry (LADI-MS). Forensic Chemistry, 15, 100173.

https://doi.org/10.1016/j.forc.2019.100173

Francese, S., Bradshaw, R., Ferguson, L. S., Wolstenholme, R., Clench, M. R., \& Bleay S. (2013) Beyond the Ridge Pattern: Multi-Informative Analysis of Latent Fingermarks by MALDI Mass Spectrometry. Analyst, 138, 4215-4228. https://doi.org/10.1039/c3an36896c

Francese, S., \& Bradshaw R. (in press). New chemical Imaging approaches to fingermark dating by Mass Spectrometry. In J. Fossoul (Ed), Technologies for Fingermark age estimations: strengthening the reliability of Fingermarks as evidence, Springer.

Francese, S. (2015). Techniques for fingermark analysis using MALDI MS - a practical overview. In R. Kramer (Ed), Advances in MALDI and laser induced soft ionisation mass spectrometry. Springer.

Francese, S. (2019). Criminal profiling through MALDI MS based technologies - breaking barriers towards border free forensic science. Australian Journal of Forensic Sciences, 51(6), 623-635. https://doi.org/10.1080/00450618.2018.1561949

Frascione, N., Thorogate, R., Daniel, B., \& Jickells, S. (2012). Detection and identification of body fluid stains using antibody-nanoparticle conjugates, Analyst, 137, 508-512. https://doi.org/10.1039/C1AN15200A

Frick, A. A., Chidlow, G., Goodpaster, J.V., Lewis, S.W., \& van Bronswijk, W. (2016). Monitoring compositional changes of the lipid fraction of fingermark residues deposited on paper during storage. Forensic Chemistry, 2, 29-36. https://doi.org/10.1016/i.forc.2016.09.001

Frick, A.A., \& Weyermann, C. (2019). An untargeted lipidomic approach for qualitative determination of latent fingermark glycerides using UPLC-IMS-QToF-MSE. Analyst, 144(11), 3590-3600.

https://doi.org/10.1039/C9AN00521H

Fritz, P., van Bronswjik, W., Lepkova, K., Lewis, S.W., Lim, K. F., Martin, D. E., \& Puskar, L. (2013). Infrared microscopy studies of the chemical composition of latent fingermark residues. Microchemical Journal, 111, 40-46. https://doi.org/10.1016/j.microc.2012.08.005 
Gallidabino, M.D., Irlam, R.C., Salt, M.C., O'Donnell, M., Beardah, M.S. \& Barron, L.P. (2019). Targeted and non-targeted forensic profiling of black powder substitutes and gunshot residue using gradient ion chromatography - high resolution mass spectrometry (IC-HRMS). Analytica Chimica Acta, 1072, 1-14. https://doi.org/10.1016/i.aca.2019.04.048

Galton, F. (1892). Finger Prints. MacMillan.

Garner, D. D., Cano, K. M., Peimer, R. S., \& Yeshion, T. E. (1976). An Evaluation of Tetramethylbenzidine as a Presumptive Test for Blood. Journal of Forensic Sciences, 21(4), 816-821. https://doi.org/10.1520/JFS10566J

Garrett, H. J., \& Bleay, S. M. (2013). Evaluation of the solvent black 3 fingermark enhancement reagent: part 1 - investigation of fundamental interactions and comparisons with other lipid-specific reagents. Science \& Justice, 53(2), 121-30. https://doi.org/10.1016/j.scijus.2012.11.006

Gaskell, C., Bleay, S. M., Willson, H., \& Park, S., (2013). Enhancement of Fingermarks on GreaseContaminated, Nonporous Surfaces: A Comparative Assessment of Processes for Light and Dark Surfaces. Journal of Forensic Identification, 63(3), 286-319.

Gilchrist, E., Smith, N., \& Barron, L. (2012). Probing gunshot residue, sweat and latent human fingerprints with capillary-scale ion chromatography and suppressed conductivity detection. Analyst, 137, 1576-1583. https://doi.org/10.1039/C2AN16126E

Girod, A., Ramotowski, R., Lambrechts, S., Misrielal, P., Aalders, M., \& Weyermann, C. (2016). Fingermark age determinations: Legal considerations, review of the literature and practical propositions. Forensic Science International, 262, 212-226.

https://doi.org/10.1016/i.forsciint.2016.03.021.

Girod, A., Spyratou, A., Holmes, D., \& Weyermann, C., (2016). Aging of target lipid parameters in fingermark residue using $\mathrm{GC} / \mathrm{MS}$ : Effects of influence factors and perspectives for dating purposes. Science \& Justice, 56(3), 165-180. https://doi.org/10.1016/i.scijus.2015.12.004

Girod, A., Xiao, L., Reedy, B., Roux, C., \& Weyermann, C. (2015). Fingermark initial composition and aging using Fourier transform infrared microscopy ( $\mu$-FTIR). Forensic Science International, 254,185196. https://doi.org/10.1016/i.forsciint.2015.07.022

Godsell, J., (1963). Fingerprint Techniques. Journal of the Forensic Science Society, 3(2), 79-87

Goode, G. C., \& Morris, J. R. (1983). Latent Fingerprints: A Review of Their Origin, Composition and Methods for Detection (Report No. O 22/83). Atomic Weapons Research Establishment.

Goode, G. C., Morris, J. R., \& Wells, J. M. (1979). The Application of Radioactive Bromine Isotopes for the Visualisation of Latent Fingerprints. Journal of Radioanalytical Chemistry, 48, 17-28. https://doi.org/10.1007/BF02519770

Goucher, E., Kicman, A., Smith, N., \& Jickells, S. (2009). The detection and quantification of lorazepam and its 3-O-glucuronide in fingerprint deposits by LC-MS/MS. Journal of Separation Science, 32(13), 2266-2272. https://doi.org/10.1002/jssc.200900097 
Grant, A., Wilkinson, T. J., Holman, D. R., \& Martin, M. C. (2005) Identification of Recently Handled Materials by Analysis of Latent Human Fingerprints Using Infrared Spectromicroscopy. Applied Spectroscopy, 59(9), 1182-1187. https://doi.org/10.1366/0003702055012618

Gray, A. C. (1978). Measurement of the Efficiency of Lipid Sensitive Fingerprint Reagents (SCS Report No 520), Atomic Weapons Research Establishment.

Grigg, R., Mongkolaussavaratana, T., Pounds, C. A., \& Sivagnanam, S. (1990). 1,8-Diazafluorenone and Related Compounds. A New Reagent for The Detection of ?-Amino Acids and Latent Fingerprints. Tetrahedron Letters, 31(49), 7215-7218. https://doi.org/10.1016/S00404039(00)97283-6

Groeneveld, G., de Puit, M., Bleay, S., Bradshaw, R., \& Francese, S. (2015). Detection and mapping of illicit drugs and their metabolites in fingermarks by MALDI MS and compatibility with forensic techniques. Science Reports, 5, 11716. https://doi.org/10.1038/srep11716

Haines, A. M., Tobe, S. S., Kobus, H. \& Linacre, A. (2015). Finding DNA: Using fluorescent in situ detection. Forensic Science International: Genetics Supplement Series, 5, e501-e502.

https://doi.org/10.1016/i.fsigss.2015.09.198

Hansen, D.B. \& Joullié, M.M. (2005) The development of novel ninhydrin analogues. Chemical Society Reviews, 34, 408-417. https://doi.org/10.1039/B315496N

Hartzell-Baguley, B., Hipp, R.E., Morgan, N.R. \& Morgan, S.L. (2007). Chemical composition of latent fingerprints by gas chromatography-mass spectrometry. An experiment for an instrumental analysis course. Journal of Chemical Education, 84 (4), 689-691. https://doi.org/10.1021/ed084p689

Hauze, D. B., Petrovskaia, O., Taylor, B., Joullie, M. M., Ramatowski, R., \& Cantu, A. A. (1998). 1,2indandiones: new reagents for visualising the amino acid components of latent prints. Journal of Forensic Sciences, 43(4), 744-7. https://doi.org/10.1520/JFS14300J

Hazarika P., Jickells S. M., Wolff K. \& Russell D. A. (2008). Imaging of latent fingerprints through the detection of drugs and metabolites. Angewandte Chemie (International ed. in English), 47, 1016710170. https://doi.org/10.1002/anie.200804348

Hazarika, P., Jickells, S. M., \& Russell, D. A. (2009). Rapid detection of drug metabolites in latent fingermarks. Analyst, 134, 93-96. https://doi.org/10.1039/B816273E

Hazarika, P., Jickells, S.M., Wolff, K. \& Russell, D.A. (2010). Multiplexed detection of metabolites of narcotic drugs from a single latent fingermark. Analytical Chemistry, 82, 9150-9154

https://doi.org/10.1021/ac1023205

Henry, E.R. (1901) Classification And Uses Of Finger Prints. Her Majesty's Stationery Office

Hinners, P., O'Neill, K. C., Lee, Y. J. (2018). Revealing Individual Lifestyles through Mass Spectrometry Imaging of Chemical Compounds in Fingerprints. Science Reports, 8(1), 5149.

https://doi.org/10.1038/s41598-018-23544-7 
Hinners, P., Thomas, M., \& Lee, Y. J. (2020). Determining Fingerprint Age with Mass Spectrometry Imaging via Ozonolysis of Triacylglycerols. Analytical Chemistry, 92(4), 3125-3132.

https://doi.org/10.1021/acs.analchem.9b04765

Hoile, R., Banos, C., Colella, M., Walsh, S.J., \& Roux, C. (2010). Gamma Irradiation as a Biological Decontaminant and Its Effect on Common Fingermark Detection Techniques and DNA Profiling. Journal of Forensic Sciences, 55(1), 171-177. https://doi.org/10.1111/i.1556-4029.2009.01233.x

Holland V R, Saunders B C, Rose F L, Walpole A L 'A Safer Substitute for Benzidine in the Detection of Blood', Tetrahedron, vol 30, (1974), p3299 - 3302.

Hudson, M., Stuchinskaya, T., Ramma, S., Patel, J., Sievers, C., Goetz, S., Hines, S., Menzies, E., \& Russell, D. A. (2019). Drug screening using the sweat of a fingerprint: lateral flow detection of $\Delta 9$ tetrahydrocannabinol, cocaine, opiates and amphetamine. Journal of Analytical Toxicology, 43(2), 88-95. https://doi.org/10.1093/jat/bky068

Ifa, D. R., Manicke, N. E., Dill, A. L., \& Cooks, R. G. (2008). Latent fingerprint chemical imaging by mass spectrometry. Science, 8, 321. http://doi.org/ 10.1126/science.1157199

Ismail, M., Stevenson, D., Costa, C., Webb, R., de Puit, M., \& Bailey, M. (2018). Noninvasive Detection of Cocaine and Heroin Use with Single Fingerprints: Determination of an Environmental Cutoff. Clinical Chemistry, 64(6), 909-917. https://doi.org/10.1373/clinchem.2017.281469

Jaber, N., Lesniewski, A., Gabizon, H., Shenawi, S., Mandler, D., \& Almog, J. (2012). Visualization of Latent Fingermarks by Nanotechnology: Reversed Development on Paper-A Remedy to the Variation in Sweat Composition. Angewandte Chemie International Edition, 51(49), 12224-12227. https://doi.org/10.1002/anie.201205259

Jacob, S., Jickells, S., Wolff K., \& Smith, N. (2008). Drug testing by chemical analysis of fingerprint deposits from methadone-maintained opioid dependent patients using UPLC-MS/MS. Drug Metabolism Letters, 2(4), 245-247. https://doi.org/10.2174/187231208786734094

Jang, M., Costa, C., Bunch, J., Gibson, B., Ismail, M., Palitsin, V., Webb, R., Hudson, M., \& Bailey, M. J. (2020). On the relevance of cocaine detection in a fingerprint. Scientific Reports, 10, 1974. https://doi.org/10.1038/s41598-020-58856-0

Jelly, R., Lewis, S. W., Lennard, C., Lim, K. F., \& Almog, J. (2008). Lawsone: a novel reagent for the detection of latent fingermarks on paper surfaces. Chemical Communications, 39(45), 3513-3515. https://doi.org/10.1039/B808424F

Jones, B., Reynolds, A.J., Richardson, M., \& Sears, V.G. (2010). Nano-scale composition of commercial white powders for development of latent fingerprints on adhesives. Science \& Justice, 50(3), 150-155. https://doi.org/10.1016/i.scijus.2009.08.001

Jones, N., Kelly, M., Stoilovic, M., Lennard, C., \& Roux, C. (2003). The development of latent fingerprints on polymer banknotes. Journal of Forensic Identification, 53(1), 50-77

Joullié, M. M., Thompson, T. R., \& Nemeroff, N. H. (1991). Ninhydrin and Ninhydrin Analogs. Syntheses and Applications. Tetrahedron 47(42), 8791-8830. https://doi.org/10.1016/S00404020(01)80997-2 
Kamanna, S., Henry, J., Voelcker, N., Linacre, A., \& Kirkbride, K. P. (2017). "Bottom-up" in situ proteomic differentiation of human and non-human haemoglobins for forensic purposes by matrixassisted laser desorption/ionization time-of-flight tandem mass spectrometry. Rapid Communications in Mass Spectrometry, 31(22), 1927-1937. https://doi.org/10.1002/rcm.7986

Kanokwongnuwut, P., Kirkbride, K. P., \& Linacre, A. (2018a) Detection of latent DNA. Forensic Science International: Genetics, 37, 95-101. https://doi.org/10.1016/j.fsigen.2018.08.004

Kanokwongnuwut, P., Kirkbride, K. P. \& Linacre, A. (2018b). Speed of accumulation of DNA in a fingermark. Australian Journal of Forensic Sciences, https://doi.org/10.1080/00450618.2018.1533039

Kanokwongnuwut, P., Kirkbride, K. P., Kobus, H., \& Linacre, A. (2019) Enhancement of fingermarks and visualizing DNA. Forensic Science International, 300, 99-105.

https://doi.org/10.1016/i.forsciint.2019.04.035

Kaplan-Sandquist, K., LeBeau, M.A., \& Miller, M.L. (2014). Chemical analysis of pharmaceuticals and explosives in fingermarks using matrix-assisted laser desorption ionization/time-of-flight mass spectrometry. Forensic Science International, 235, 68-77.

https://doi.org/10.1016/i.forsciint.2013.11.016

Kaplan-Sandquist, K., LeBeau, M.A., \& Miller, M.L. (2015). Evaluation of four fingerprint development methods for touch chemistry using matrix-assisted laser desorption ionization/time-of-flight mass spectrometry. Journal of Forensic Sciences, 60(3), 611-618. https://doi.org/10.1111/1556$\underline{4029.12718}$

Keisar, O., Cohen, Y., Finkelstein, Y., Kostirya, N., Ben-David, R., Danon, A., Porat, Z., \& Almog, J. (2019). Measuring the water content in freshly-deposited fingermarks. Forensic Science International, 294, 204-210. https://doi.org/10.1016/i.forsciint.2018.11.017

Kennedy, K., Heaton, H., Langenburg, G., Cole, L., Clark, T., Clench, M. R., Sears, V., Sealey, M., McColm, R., \& Francese, S. (2020). Pre-validation of a MALDI MS proteomics-based method for the reliable detection of blood and blood provenance Scientific Reports, submitted

Kent, T. (Ed.) (1986). Manual of Fingerprint Development Techniques. Home Office Scientific Research and Development Branch.

Kent, T. (2016) Water content of latent fingerprints - Dispelling the myth. Forensic Science International, 266,134-138. https://doi.org/10.1016/i.forsciint.2016.05.016

Kim, Y., Choi, W-s., Choi, E.J., Jeon, B., Kim, J., Park, G.H., Huang, Y., Wufuer, M., Jin, X., Kim, M.O., Xu, L., Piao, Y.L., Park, J.H., Kim, W-K., \& Choi, T.H. (2019) Evaluation of fatty acids in groomed fingerprint by gas chromatographic analysis using various extraction solvents and treatments. Journal of Analytical Science and Technology, 10, 29. https://doi.org/10.1186/s40543-019-0188-y 
Kim, Y, Choi, W-S, Jeon, B. \& Choi, T.H. (2020). The effect of temperature and exposure time on stability of cholesterol and squalene in latent fingermarks deposited on PVDF membrane. Journal of Forensic Sciences, 65(2), 458-464. https://doi.org/10.1111/1556-4029.14209

Koenig, A., Girod, A., \& Weyermann, C. (2011). Identification of wax esters in latent print residues by gas chromatography-mass spectrometry and their potential use as aging parameters, Journal of Forensic Identification, 61(6), 606-631.

Kovacs, E.M.R., Stegen, J.H.C.H., \& Brouns, F. (1998). Effect of caffeinated drinks on substrate metabolism, caffeine excretion, and performance. Journal of Applied Physiology, 85, 709-715. https://doi.org/10.1152/jappl.1998.85.2.709

Kupferschmid, E., Schwarz, L., \& Champod, C. (2010). Development of Standardized Test Strips as a Process Control for the Detection of Latent Fingermarks using Physical Developers. Journal of Forensic Identification, 60(6), 639-65.

Kuwayama, K., Tsujikawa, K., Miyaguchi, H., Kanamori, T., Iwata, Y. T., \& Inoue, H. (2013). Timecourse measurements of caffeine and its metabolites extracted from fingertips after coffee intake: a preliminary study for the detection of drugs from fingerprints. Analytical and Bioanalytical Chemistry, 405(12), 3945-3952. https://doi.org/10.1007/s00216-012-6569-3

Kuwayama, K., Yamamuro, T., Tsujikawa, K., Miyaguchi, H., Kanamori, T., Iwata, Y. T., \& Inoue, H. (2014). Time-course measurements of drugs and metabolites transferred from fingertips after drug administration: usefulness of fingerprints for drug testing. Forensic Toxicology, 32, 235-242. https://doi.org/10.1007/s11419-014-0228-7

Lam, R., Wilkinson, D., Tse, T., Pynn, B. (2014). Recommended protocols for fingerprint detection on Canadian polymer banknotes - Part I: Chemical development. Journal of Forensic Identification, 64(4), 375-401.

Lauzon, N., Dufresne, M., Beaudoin, A., \& Chaurand, P. (2017). Forensic analysis of latent fingermarks by silver-assisted LDI imaging MS on nonconductive surfaces. Journal of Mass Spectrometry, 52(6), 397-404. https://doi.org/10.1002/jms.3938

Lauzon, N., \& Chaurand, P. (2018). Detection of exogenous substances in latent fingermarks by silver-assisted LDI imaging MS: perspectives in forensic sciences. Analyst, 143(15), 3586-3594. https://doi.org/10.1039/C8AN00688A

Lee, H. C., \& Attard, A. E. (1979). Comparison of Fluorescamine, O-phthalaldehyde, and Ninhydrin for the Detection and Visualization of Latent Fingerprints. Journal of Police Science \& Administration, 7(3), 333-335

Leggett, R., Lee-Smith, E. E., Jickells., S. M., \& Russell, D. A. (2007). Intelligent Fingerprinting: Simultaneous Identification of Drug Metabolites and Individuals by Using Antibody-Functionalized Nanoparticles. Angewandte Chemie International Edition, 46(22), 4100-4103. https://doi.org/10.1002/anie.200700217 
Lennard, C. J., Margot, P. A., Stoilovic, M., \& Warrener, R. N. (1986). Synthesis of Ninhydrin Analogues and Their Application to Fingerprint Development: Preliminary Results. Journal of the Forensic Science Society, 26, 323-8. https://doi.org/10.1016/S0015-7368(86)72510-3

Lennard, C. J., Margot, P. A., Sterns, M., \& Warrener, R. N. (1987). Photoluminescent Enhancement of Ninhydrin Developed Fingerprints by Metal Complexation: Structural Studies of Complexes Formed Between Ruhemann's Purple and Group Ilb Metal Salts. Journal of Forensic Sciences, 32(3), 597-605. https://doi.org/10.1520/JFS12364J

Lennard, C. J., \& Margot, P. A., (1988). Sequencing of Reagents for the Improved Visualisation of Latent Fingerprints. Journal of Forensic Identification, 38(5), 197-208.

Lewis, L. A., Smithwick, R. W. III, Devault, G. L., Bolinger, B., \& Lewis, S. A. Sr. (2001). Processes Involved in the Development of Latent Fingerprints Using the Cyanoacrylate Fuming Method. Journal of Forensic Sciences, 46(2), 241-6. https://doi.org/10.1520/JFS14956J

Li, K., Qin, W., Zhao, X., Jiang, B., Wang, K., Deng, S., Fan, C. \& Li, D. (2013) Nanoplasmonic imaging of latent fingerprints and identification of cocaine. Angewandte Chemie International, 52(44) 1154211545 https://doi.org/10.1002/anie.201305980

Liappis, N., \& Hungerland, H. (1973) The trace amino acid pattern in human eccrine sweat. Clinica Chimica Acta, 48, 233-236. https://doi.org/10.1016/0009-8981(73)90371-9

Lim, A.Y. \& Seviour, J. (2012). Doped silica nanoparticles for the detection of pharmaceutical terbinafine in latent fingerprints by mass spectrometry. Analytical Methods, 4, 1983-1988 https://doi.org/10.1039/C2AY25187F

Lim, A.Y., Rowell, F., Elumbaring-Salazar, C.G., Loke, J. \& Ma, J. (2013). Detection of drugs in latent fingermarks by mass spectrometric methods. Analytical Methods, 5, 4378-4385 https://doi.org/10.1039/c3ay40538a

Linde, H. G. (1975). Latent Fingerprints by a Superior Ninhydrin Method. Journal of Forensic Sciences, 20, 581-4. https://doi.org/10.1520/JFS10307J

Love, C., Gilchrist, E., Smith, N., \& Barron, L. (2013). Detection of anionic energetic material residues in enhanced fingermarks on porous and non-porous surfaces using ion chromatography. Forensic Science International, 231, 150-156. https://doi.org/10.1016/i.forsciint.2013.04.017

Lucena, P., Gaona, I., Moros, J. \& Laserna, J.J. (2013). Location and detection of explosivecontaminated human fingerprints on distant targets using standoff laser-induced breakdown spectroscopy. Spectrochimica Acta Part B, 85, 71-77 https://doi.org/10.1016/j.sab.2013.04.003

Malka, I., Petrushansky, A., Rosenwaks, S. \& Bar, I. (2013) Detection of explosives and latent fingerprint residues utilizing laser pointer-based Raman spectroscopy. Applied Physics B, 113, 511518 https://doi.org/10.1007/s00340-013-5500-8

Mangle, M. F., Xu, X., \& de Puit, M. (2015). Performance of 1, 2-indanedione and the need for sequential treatment of fingerprints. Science \& Justice, 55(5), 343-6.

https://doi.org/10.1016/j.scijus.2015.04.002 
Marriott, C., Lee, R., Wilkes, Z., Comber, B., Spindler, X., Roux, C., \& Lennard, C. (2014). Evaluation of fingermark detection sequences on paper substrates. Forensic Science International, 236, 30-7. https://doi.org/10.1016/i.forsciint.2013.12.028

McBean, R. S., Hyland, C. A., \& Flower, R. L. (2015). Blood group genotyping: the power and limitations of the Hemo ID Panel and MassARRAY platform. Immunohematology, 31(2), 75-80.

McLaren, C., Lennard, C., \& Stoilovic, M. (2010). Methylamine Pretreatment of Dry Latent Fingermarks on Polyethylene for Enhanced Detection by Cyanoacrylate Fuming. Journal of Forensic Identification, 60(2), 199-222.

McMullen, L., \& Beaudoin, A. (2013). Application of Oil Red O Following DFO and Ninhydrin Sequential Treatment: Enhancing Latent Fingerprints on Dry, Porous Surfaces. Journal of Forensic Identification, 63(4), 387-423.

Mirabelli, M. F., Chramow, A., Cabral, E. C., \& Ifa, D. R. (2013). Analysis of sexual assault evidence by desorption electrospray ionization mass spectrometry. Journal of Mass Spectrometry, 48(7), 774-8. https://doi.org/10.1002/ims.3205

Mitchell, C. A. (1920). The Detection of Fingerprints on Documents. Analyst, 45, 122-9.

Montgomery, L., Spindler, X., Maynard, P., Lennard, C., \& Roux, C. (2012) Pretreatment Strategies for the Improved Cyanoacrylate Development of Dry Latent Fingerprints on Nonporous Surfaces. Journal of Forensic Identification, 62(5), 517-542.

Moore, J., Bleay, S., Deans, J., \& nic Daeid, N. (2008). Recovery of fingerprints from arson scenes:

Part 2 -fingerprints in blood. Journal of Forensic Identification, 58(1), 83-108.

Moret, S., Spindler, X., Lennard, C., \& Roux, C. (2015). Microscopic examination of fingermark residues: Opportunities for fundamental studies. Forensic Science International, 255, 28-37. https://doi.org/10.1016/i.forsciint.2015.05.027

Morris, J.R., Goode, G.C. \& Godsell, J.W. (1973). Some new developments in the chemical development of latent fingerprints. Police Research Bulletin, 21, 31-36

Mou, Y., \& Rabalais, J. W. (2009). Detection and Identification of Explosive Particles in Fingerprints Using Attenuated Total Reflection-Fourier Transform Infrared Spectromicroscopy. Journal of Forensic Sciences, 54(4), 846-850. https://doi.org/10.1111/i.1556-4029.2009.01060.x

Moule, E.C., Guinan, T.M., Gustafsson, O.J.R., Kobus, H., Kirkbride,, K.P.\& Voelcker, N.H. (2017). Silver-assisted development and imaging of fingermarks on non-porous and porous surfaces. International Journal of Mass Spectrometry, 422, 27-31 http://dx.doi.org/10.1016/j.ijms.2017.08.001

Mountfort, K. A., Bronstein, H., Archer, N., \& Jickells, S. M. (2007). Identification of oxidation products of squalene in solution and in latent fingerprints by ESI-MS and LC/APCI-MS. Analytical Chemistry, 79(7), 2650-7. https://doi.org/10.1021/ac0623944 
Murakami, M. Ohtake, T., Dorschner, R.A., Schittek, B., Garbe, C., \& Gallo, R.L. (2002). Cathelicidin anti-microbial peptide expression in sweat, an innate defense system for the skin. Journal of Investigative Dermatology, 119, 1090-1095. https://doi.org/10.1046/i.1523-1747.2002.19507.x

Muramoto, S., \& Sisco, E. (2015). Strategies for Potential Age Dating of Fingerprints through the Diffusion of Sebum Molecules on a Nonporous Surface Analyzed Using Time-of-Flight Secondary Ion Mass Spectrometry. Analytical Chemistry, 87(16), 8035-8038.

https://doi.org/10.1021/acs.analchem.5b02018

Muramoto, S., Forbes, T.P., van Asten, A.C \&, Gillen, G. (2015). Test sample for the spatially resolved quantification of illicit drugs on fingerprints using imaging mass spectrometry. Analytical Chemistry, 87(10) 5444-5450 https://doi.org/10.1021/acs.analchem.5b01060.

Nakayashiki, N. (1990). Sweat protein components tested by SDS-polyacrylamide gel electrophoresis following by immunoblotting. Tohoku Journal of Experimental Medicine, 161, 25-31.

https://doi.org/10.1620/tjem.161.25

Nazzaro-Porro, M., Passi, S., Boniforti, L., \& Belsito, F. (1979). Effects of aging on fatty acids on skin surface lipids. Journal of Investigative Dermatology, 73, 112-117. https://doi.org/10.1111/15231747.ep12532793

Nicolaides, N. (1974) Skin lipids: their biochemical uniqueness, Science, 186, 19-26. https://doi.org/10.1126/science.186.4158.19

Ng, P. H. R., Walker, S., Tahtouh, M., \& Reedy, B. (2009) Detection of illicit substances in fingerprints by infrared spectral imaging.Analytical and Bioanalytical Chemistry, 394, 2039-2048.

https://doi.org/10.1007/s00216-009-2806-9

Norkus, P., \& Noppinger, K. (1986). New Reagent for the Enhancement of Blood Prints. Identification News, 26(4), 5.

Oden, S., \& von Hofsten, B. (1954). Detection of Fingerprints by the Ninhydrin Reaction. Nature, March 6, 449-450. https://doi.org/10.1038/173449a0

Oleiwi, A.A., Morris, M.R., Schmerer, W.M., \& Sutton, R. (2015). The relative DNA-shedding propensity of the palm and finger surfaces. Science \& Justice, 55(5), 329-334. https://doi.org/10.1016/j.scijus.2015.04.003

Olsen, R.D. (1972). The chemical composition of palmar sweat. Fingerprint Identification Magazine, 53, 3-16.

Olsen, R. D. Sr. (1987). Chemical Dating Techniques for latent Fingerprints: A Preliminary Report. Identification News, 4-5, 12.

Page, C. O., \& Remington, J.S. (1967). Immunologic studies in normal human sweat. Journal of Laboratory \& Clinical Medicine, 69, 634-650.

O'Neal Page, C. , \& Remington, J.S. (1967). Immunologic studies in normal human sweat. Journal of Laboratory \& Clinical Medicine, 69, 634-650. 
O'Neill, K. C., \& Lee, Y, J. (2018). Effect of Aging and Surface Interactions on the Diffusion of Endogenous Compounds in Latent Fingerprints Studied by Mass Spectrometry Imaging. Journal of Forensic Sciences, 63(3), 708-713. https://doi.org/10.1111/1556-4029.13591

O'Neill, K.C., Hinners, P., \& Lee, Y.J. (2020). Potential of triacylglycerol profiles in latent fingerprints to reveal individual diet, exercise or health information for forensic evidence. Analytical Methods, 12, 792-798. https://doi.org/10.1039/C9AY02652E

Oonk, S., Schuurmans, T., Pabst, M., de Smet, L. C. P. M., \& de Puit, M. (2018). Proteomics as a new tool to study fingermark ageing in forensics. Scientific Reports, 8, 16425.

https://doi.org/10.1038/s41598-018-34791-z

Paine, M., Bandey, H. L., Bleay, S. M., \& Willson, H. (2011). The effect of relative humidity on the effectiveness of the cyanoacrylate fuming process for fingermark development and on the microstructure of the developed marks. Forensic Science International, 212(1), 130-142. https://doi.org/10.1016/j.forsciint.2011.06.003

Park, H. G., Jang, K. S., Park, H. M., Song, W. S., Jeong, Y. Y., Ahn, D. H., Kim, S. M., Yang, Y. H., \& Kim, Y.G. (2019). MALDI-TOF MS-based total serum protein fingerprinting for liver cancer diagnosis. Analyst, 144(7). 2231-2238. https://doi.org/10.1039/c8an0224

Patel, E., Clench, M. R., West, A., Marshall, P. S., Marshall, N., \& Francese S. (2015). Alternative surfactants for improved efficiency of in situ tryptic proteolysis of fingermarks. Journal of the American Society of Mass Spectrometry, 26(6), 862-72. https://doi.org/10.1007/s13361-015-1140-z

Patel, E., Cicatiello, P., Deininger, L., Clench, M.R., Marino, G., Giardina, P., Langenburg, G., West, A., Marshall, P., Sears, V., \& Francese, S. (2016) A proteomic approach for the rapid, multi-informative and reliable identification of blood. Analyst, 141(1),191-8. https://doi.org/10.1039/C5AN02016F

Pleik, S., Spengler, B., Bhandari, D. R., Luhn, S., Schäfer, T., Urbach, D. \& Kirsch, D. (2018). Ambientair ozonolysis of triglycerides in aged fingerprint residues. Analyst, 143, 1197-1209. https://doi.org/10.1039/C7AN01506B

Pluháček, T., Švidrnocha, M., Maier, V., Havlíček, V., Lemr, K. (2018). Laser ablation inductively coupled plasma mass spectrometry imaging: A personal identification based on a gunshot residue analysis on latent fingerprints. Analytica Chimica Acta, 1030, 25-32.

https://doi.org/10.1016/j.aca.2018.05.074

Popolan-Vaida, D. M., Wilson, K. R., \& Leone, S. R. (2014). Reaction of lodine Atoms with Submicrometer Squalane and Squalene Droplets: Mechanistic Insights into Heterogeneous Reactions. Journal of Physical Chemistry A, 118(45), 10688-10698. https://doi.org/10.1021/ip5085247

Porpiglia, N., Bleay, S., Fitzgerald, L., \& Barron, L. (2012). An assessment of the effectiveness of 5methylthioninhydrin within dual action reagents for latent fingerprint development on paper substrates. Science \& Justice, 52(1), 42 - 48. https://doi.org/10.1016/i.scijus.2011.04.006 
Préstamo, G., \& Manzano, P. (1993). Peroxidases of Selected Fruits and Vegetables and the Possible Use of Ascorbic Acid as an Antioxidant. Horticultural Science, 28(1), 48-50.

https://doi.org/10.21273/HORTSCI.28.1.48

Quinche, N., \& Margot, P. (2010). Coulier, Paul-Jean (1824-1890): A Precursor in the History of Fingermark Detection and Their Potential Use for Identifying Their Source (1863). Journal of Forensic Identification, 60(2),129-134

Quinones, I., \& Daniel, B. (2012). Cell free DNA as a component of forensic evidence recovered from touched surfaces. Forensic Science International: Genetics, 6(1), 26-30.

https://doi.org/10.1016/j.fsigen.2011.01.004

Reed, H., Stanton, A., Wheat, J., Kelley, J., Davis, L., Rao, W., Smith, A., Owen, D., \& Francese, S. (2016). The Reed-Stanton press rig for the generation of reproducible fingermarks: Towards a standardised methodology for fingermark research. Science \& Justice, 56(1), 9-17.

https://doi.org/10.1016/j.scijus.2015.10.001

Ricci, C., Chan, K. L. A., \& Kazarian, K. G. (2006). Combining the Tape-Lift Method and Fourier Transform Infrared Spectroscopic Imaging for Forensic Applications. Applied Spectroscopy, 60(9) 1013-1021. https://doi.org/10.1366/000370206778397434

Ricci, C., \& Kazarian, S. G. (2010). Collection and detection of latent fingermarks contaminated with cosmetics on nonporous and porous surfaces. Surface and Interface Analysis, 42, 386-392.

https://doi.org/10.1002/sia.3098

Richmond-Aylor, A., Bell, S., Callery P., \& Morris, K. (2007). Thermal Degradation Analysis of Amino Acids in Fingerprint Residue by Pyrolysis GC-MS to Develop New Latent Fingerprint Developing Reagents. Journal of Forensic Sciences, 52(2), 380-382. https://doi.org/10.1111/j.1556-

$\underline{4029.2007 .00384 . x}$

Robertshaw, D. (1991). Apocrine sweat glands. In L.A. Goldsmith (Ed.) Physiology, Biochemistry and Molecular Biology of the Skin, (pp 763-775) Oxford University Press.

Rothman, S. (1954). Physiology and Biochemistry of the Skin, University of Chicago Press.

Rowell, K., Hudson, K., \& Seviour, J. (2009). Detection of drugs and their metabolites in dusted latent fingermarks by mass spectrometry. Analyst, 134, 701-707. https://doi.org/10.1039/B813957C

Rowell, F., Seviour, J., Lim, A.Y., Elumbaring-Salazar, C.G., Loke, J, \& Ma, J. (2012). Detection of nitroorganic and peroxide explosives in latent fingermarks by DART- and SALDI-TOF- mass spectrometry. Forensic Science International, 221, 84-91. https://doi.org/10.1016/i.forsciint.2012.04.007

Ruhemann, S. (1910). Triketohydrindene Hydrate. Journal of Chemistry Society Transactions, 97, 2025-2031 
Saga, K. (2002). Structure and function of human sweat glands studied with histochemistry and cytochemistry. Progress in Histochemistry \& Cytochemistry, 37(4), 323-386.

https://doi.org/10.1016/S0079-6336(02)80005-5

Salama, J., Aumeer-Donovan, S., Lennard, C., \& Roux, C. (2008). Evaluation of the Fingermark Reagent Oil Red $\mathrm{O}$ as a Possible replacement for Physical Developer. Journal of Forensic Identification, 58(2), 203-237.

Scruton, B., Robins, B.W. \& Blott, B.H. (1975). The deposition of fingerprint films. Journal of Physics D: Applied Physics, 8, 714-723

Sears, V. G., \& Prizeman, T. M. (2000). The Enhancement of Fingerprints in Blood - Part 1: The Optimization of Amido Black. Journal of Forensic Identification, 50(5), 470-480.

Sears, V. G., Butcher, C. P. G., \& Prizeman, T. M. (2001). The Enhancement of Fingerprints in Blood Part 2: Protein Dyes'. Journal of Forensic Identification, 51(1), 28-38.

Sears, V., Butcher, C., \& Fitzgerald, L. (2005). Enhancement of Fingerprints in Blood - Part 3 Reactive Techniques, Acid Yellow 7 and Process Sequences. Journal of Forensic Identification, 55(6), 741-763.

Sears, V. G., Bleay, S. M., Bandey, H. L., \& Bowman, V. J. (2012), A Methodology for Finger Mark Research. Science \& Justice, 52(3), 145-160. https://doi.org/10.1016/j.scijus.2011.10.006

Skriba, A., \& Havlicek, V. (2018). Mass spectrometry imaging of illicit drugs in latent fingerprints by matrix-free and matrix-assisted desorption/ionization techniques. European Journal of Mass Spectrometry, 24(1). https://doi.org/10.1177/1469066717728007

Song, W., Mao, Z., Liu, X., Lu, Y., Li, Z., Zhao, B. and Lu, L. (2012) Detection of protein deposition within latent fingerprints by surface-enhanced Raman spectroscopy imaging. Nanoscale, 4, 23332338

Souza, M.A., de Oliveira, K.V., Oliveira, F.C.C., Silva, L.P. \& Rubim, J.C. (2018) The adsorption of methamphetamine on Ag nanoparticles dispersed in agarose gel - Detection of methamphetamine in fingerprints by SERS. Vibrational Spectroscopy, 98, 152-157

https://doi.org/10.1016/i.vibspec.2018.08.008

Spindler, X., Stoilovic, M., Lennard, C., \& Lennard, A. (2009). Spectral Variations for Reaction Products Formed Between Different Amino Acids and Latent Fingermark Detection Reagents on a Range of Cellulose-Based Substrates. Journal of Forensic Identification, 59(3), 308-324.

Spindler, X., Shimmon, R., Roux, C. \& Lennard, C. (2011). The effect of zinc chloride, humidity and the substrate on the reaction of 1,2-indanedione-zinc with amino acids in latent fingermark secretions. Forensic Science International, 212, 150-157. https://doi.org/10.1016/j.forsciint.2011.06.005

Spindler, X., Shimmon, R., Roux, C. \& Lennard, C. (2015). Visualising substrate-fingermark interactions: Solid-state NMR spectroscopy of amino acid reagent development on cellulose substrates. Forensic Science International, 250, 8-16. https://doi.org/10.1016/j.forsciint.2015.02.019 
Sundar, L., \& Rowell, R. (2014). Detection of drugs in lifted cyanoacrylate-developed latent fingermarks using two laser desorption/ionisation mass spectrometric methods. Analyst, 139(3), 633-642. https://doi.org/10.1039/C3AN00969F

Sundar, L. \& Rowell, F. (2015). Drug cross-contamination of latent fingermarks during routine powder dusting detected by SALDI TOF MS. Analytical Methods, 7, 3757-3763 https://doi.org/10.1039/c5ay00598a

Szabóová, Z., Galbavá, P., Szabó, A. H., Cigáň, M., Nižnanský, L., Kubinec, R., \& Blaško, J. (2017). GCMS/MS method for age determination of fingerprints. Monatshefte für Chemie - Chemical Monthly, 148, 1673-1678. https://doi.org/10.1007/s00706-017-1984-y

Szynkowska, M.I., Czerski K., Rogowski, J., Paryjczak, T., Parczewski, A. (2009). ToF-SIMS application in the visualization and analysis of fingerprints after contact with amphetamine drugs. Forensic Science International, 184, e24-e26. https://doi.org/10.1016/i.forsciint.2008.11.003

Szynkowska, M. I., Czerski, K., Rogowski, J., Paryjczak, T., \& Parczewski, A. (2010). Detection of exogenous contaminants of fingerprints using ToF-SIMS. Surface \& Interface Analysis, 42, 393-397. https://doi.org/10.1002/sia.3193

Teale, F. W. J., \& Weber, G. (1957). Ultraviolet fluorescence of the aromatic amino acids. Biochemistry Journal, 65(3), 476-482. https://doi.org/10.1042/bj0650476

Thandauthapani, T. V., Reeve, A. J., Longblan, A. S., Turner, J. \& Sharp, J. S. (2018). Exposing latent fingermarks on problematic metal surfaces using time of flight secondary ion mass spectroscopy. Science \& Justice, 58(6), 405-414. https://doi.org/10.1016/j.scijus.2018.08.004

Theeuwen, A. B. E., van Barneveld, S.. Drok, J. W., Keereweer, I., Limborgh, J. C. M., Naber, W. M., \& Velders, T. (1998). Enhancement of Footwear Impressions in Blood. Forensic Science International, 95(2), 133-151. https://doi.org/10.1016/S0379-0738(98)00084-X

Thomas, G. L., \& Reynoldson, T. E. (1975). Some observations on fingerprint deposits. Journal of Physics D: Applied Physics, 8, p724-9.

Thomas, G. L. (1978). The physics of fingerprints and their detection. Journal of Physics E: Scientific Instruments, 11(8), 722-731.

Tripathi, A., Emmons, E.D., Wilcox, P.G., Guicheteau, J.A., Emge, D.K., Christesen, S.D., \& Fountain III, A.W. (2011). Semi-automated detection of trace explosives in fingerprints on strongly interfering surfaces with Raman chemical imaging. Applied Spectroscopy, 65, 611-619.

https://doi.org/10.1366/10-06214

van Dam, A., Aalders, M. C. G., van Leeuwen, T. G., \& Lambrechts, S. A. G. (2013a). The Compatibility of Fingerprint Visualization Techniques with Immunolabeling. Journal of Forensic Sciences, 58(4), 999-1002. https://doi.org/10.1111/1556-4029.12147 
van Dam, A., Aalders, M. C., van de Braak, K., Hardy, H. J., van Leeuwen, T. G., \& Lambrechts, S. A. (2013b). Simultaneous labeling of multiple components in a single fingermark. Forensic Science International, 232(1-3), 173-9. https://doi.org/10.1016/i.forsciint.2013.07.020

van Dam, A., Schwarz, J. C. V., de Vos, J., Siebes, M., Sijen,T., van Leeuwen, T. G., Aalders, M. C. G. \& Lambrechts, S. A. G. (2014). Oxidation monitoring by fluorescence spectroscopy reveals the age of fingermarks. Angewandte Chemie International Edition, 53, 6272-6275.

https://doi.org/10.1002/anie.201402740

van Dam, A., Aalders, M. C. G., Todorovski, T., van Leeuwen, T. G., \& Lambrechts, S. A.G. (2016). On the autofluorescence of aged fingermarks. Forensic Science International, 258, 19-25.

https://doi.org/10.1016/i.forsciint.2015.11.002

van der Heide, S., Garcia Calavia, P., Hardwick, S., Hudson, S., Wolff, K. \& Russell, D.A. (2015). A competitive enzyme immunoassay for the quantitative detection of cocaine from banknotes and latent fingermarks. Forensic Science International, 250, 1-7.

https://doi.org/10.1016/i.forsciint.2015.02.008

van Helmond, W., Kuijpers, C-J., van Diejen, E., Spiering, J., Maagdelijn, B. \& de Puit, M. (2017). Amino acid profiling from fingerprints, a novel methodology using UPLC-MS. Analytical Methods, 9, 5697-5702. https://doi.org/10.1039/C7AY01603D

van Helmond, W., Weening, M., Vleer, V., \& de Puit, M. (2020). Analysis of amino acid enantiomers from aged fingerprints (Technical Note), Analytical Methods, Advance Article http://doi.org/10.1039/DOAY00096E

Wargacki, S. P., Lewis, L. A., \& Dadmun, M. D. (2007). Understanding the Chemistry of the Development of Latent Fingerprints by Superglue Fuming. Journal of Forensic Sciences, 52(5), 10571062. https://doi.org/10.1111/i.1556-4029.2007.00527.x

Wargacki, S. P., Lewis, L. A., \& Dadmun, M. D. (2008). Enhancing the Quality of Aged Latent Fingerprints Developed by Superglue Fuming: Loss and Replenishment of Initiator. Journal of Forensic Sciences, 53(5), 1138-1144. https://doi.org/10.1111/j.1556-4029.2008.00822.x

Warrener, R. N., Kobus, H. J., \& Stoilovic, M. (1983). An Evaluation of the Reagent NBD Chloride for the Production of Luminescent Fingerprints on Paper: I. Support for a Xenon Arc Lamp Being a Cheaper and Valuable Alternative to an Argon Ion Laser as an Excitation Source. Forensic Science International, 23,179-188. https://doi.org/10.1016/0379-0738(83)90147-0

Watkinson, Shelley N. (2018) Approaches towards the quantification of caffeine and metabolites in fingerprints. [Doctoral thesis, University of Surrey]. Surrey Research Insight. http://epubs.surrey.ac.uk/845799/

West, M.J., \& Went, M. J. (2008). The spectroscopic detection of exogenous material in fingerprints after development with powders and recovery with adhesive lifters. Forensic Science International, 174(1), 1-5. https://doi.org/10.1016/i.forsciint.2007.02.026 
West, M.J., \& Went, M. J. (2009). The spectroscopic detection of drugs of abuse in fingerprints after development with powders and recovery with adhesive lifters, Spectrochimica Acta Part A, 71(5), 1984-1988. https://doi.org/10.1016/j.saa.2008.07.024

Weyermann C., Roux C., \& Champod C. (2011). Initial Results on the Composition of Fingerprints and its Evolution as a Function of Time by GC/MS Analysis. Journal of Forensic Sciences, 56(1), 102-108. https://doi.org/10.1111/j.1556-4029.2010.01523.x

Weyermann, C., \& Ribaux, O. (2012). Situating forensic traces in time. Science \& Justice, 52(2), 6875. https://doi.org/10.1016/j.scijus.2011.09.003

Wightman, G., \& O'Connor, D. (2011). The thermal visualisation of latent fingermarks on metallic surfaces. Forensic Science International, 204(1-3), 88-96.

https://doi.org/10.1016/i.forsciint.2010.05.007

Williams, G., McMurray, H. N., \& Worsley, D. A. (2001). Latent Fingerprint Detection Using a Scanning Kelvin Microprobe. Journal of Forensic Sciences, 46(5), 1085-1092.

https://doi.org/10.1520/JFS15103J

Wilkinson, D. A., Hancock, J., Lecavalier, P., \& McDiarmid, C. (2005). The Recovery of Fingerprint Evidence from Crime Scenes Contaminated with Chemical Warfare Agents. Journal of Forensic Identification, 55(3), 326-361.

Wolstenholme, R., Bradshaw, R., Clench, M. R., \& Francese, S. (2009). Study of latent fingermarks by matrix-assisted laser desorption/ionisation mass spectrometry imaging of endogenous lipids. Rapid Communications in Mass Spectrometry, 23(19), 3031-9. https://doi.org/10.1002/rcm.4218

Worley, C. G., Wiltshire, S. S., Miller, T. C., Havrilla, G. J., \& Majidi, V. J. (2006). Detection of visible and latent fingerprints using micro-x-ray fluorescence elemental imaging. Journal of Forensic Sciences, 51(1), 57-63. https://doi.org/10.1111/j.1556-4029.2005.00006.x

Yagnik, G.B., Korte, A.R \& Lee, Y.J. (2013). Multiplex mass spectrometry imaging for latent fingerprints. Journal of Mass Spectrometry, 48, 100-104. https://doi.org/10.1002/jms.3134

Yang, T., Guo, X., Wang, H., Fu, S., wen, Y., \& Yang, H. (2015). Magnetically optimized SERS assay for rapid detection of trace drug-related biomarkers in saliva and fingerprints. Biosensors and Bioelectronics, 68, 350-357. https://doi.org/10.1016/i.bios.2015.01.021

Yang, H., Li, S., Zhang, Q., Wang, Z., Li, N., Han, C., Huo, Q., \& Zhao, Z. (2019). Combination of electrospray deposition technology of TiO2 nanoparticles and MALDI FTICR MSI for identificaiton of fingerprint morphology and latent components. Talanta, 198, 310-315.

https://doi.org/10.1016/j.talanta.2019.02.007

Yeo, H. C., \& Shibamoto, T. (1992). Formation of formaldehyde and malonaldehyde by photooxidation of squalene. Lipids, 27(1), 50-3. https://doi.org/10.1007/BF02537059

Zheng, L-N., Ma, R-L., Li, Q., Sang, Y-B., Wang, H-L., Wang, B., Yan, Q-Q., Chen, D-L., Wang, M., Feng W-Y., \& Zhao, Y-L (2019). Elemental Analysis and Imaging of Sunscreen Fingermarks by X-ray 
Fluorescence. Analytical and Bioanalytical Chemistry, 411(18), 4151-4157.

https://doi.org/10.1007/s00216-019-01718-0

Zuidberg M. C., van Woerkom, T., de Bruin, K.G., Stoel, R. D., \& de Puit, M. (2014). Effects of CBRN Decontaminants in Common use by First Responders on the Recovery of Latent Fingerprints Assessment of the Loss of Ridge Detail on Glass. Journal of Forensic Sciences, 59(1), 61-69. https://doi.org/10.1111/1556-4029.12281

Further Reading

Bleay, S. M., Croxton, R. S. \& de Puit, M. (2018). Fingerprint Development Techniques: Theory and Application. Wiley. DOI:10.1002/9781119187400

Champod, C., Lennard, C. J., Margot. P., \& Stoilovic, M. (2016). Fingerprints and Other Ridge Skin Impressions, $2^{\text {nd }}$ edition. CRC Press.

Ramotowski, R. (Ed). (2012). Lee and Gaensslen's Advances in Fingerprint Technology, $3^{\text {rd }}$ edition. CRC Press.

de Hoffman, E., \& Stroobant, V. (2007). Mass Spectrometry, Principles and Applications, 3rd edition. John Wiley \& Sons Ltd.

Francese, S. (Ed). (2019). Emerging Technologies for the Analysis of Forensic Traces. Springer Nature. https://doi.org/10.1007/978-3-030-20542-3,

Francese, S., \& Russo, C. (2019). Fingermarks as a New Proteomic Specimen: State of the Art and Perspective of In Situ Proteomics. In E. Merkley, E. (Ed) Applications in Forensic Proteomics: Protein Identification and Profiling ACS Symposium Series. American Chemical Society. 